Article

\title{
Design and Synthesis of C-19 Isosteviol Derivatives as Potent and Highly Selective Antiproliferative Agents
}

\author{
Tian Luan ${ }^{1,+}{ }^{,}$Li-Hua Cao ${ }^{2,+}{ }^{+}$Hao Deng ${ }^{1}$, Qing-Kun Shen ${ }^{1}$, Yu-Shun Tian ${ }^{1, *}$ and \\ Zhe-Shan Quan 1,* \\ 1 Key Laboratory of Natural Resources and Functional Molecules of the Changbai Mountain, Affiliated \\ Ministry of Education, College of Pharmacy, Yanbian University, Yanji 133002, China; \\ sapphire0614@163.com (T.L.); 2017010676@ybu.edu.cn (H.D.); 2016001065@ybu.edu.cn (Q.-K.S.) \\ 2 Department of Pharmacology, College of Medicine, Yanbian University, Yanji 133002, China; \\ lhcao@ybu.edu.cn \\ * $\quad$ Correspondence: ystian@ybu.edu.cn (Y.-S.T.); zsquan@ybu.edu.cn (Z.-S.Q.); Tel.: +86-433-243-6020 (Z.-S.Q.); \\ Fax: + 86-433-243-6020 (Z.-S.Q.) \\ + These authors contributed equally to this work.
}

Received: 17 December 2018; Accepted: 24 December 2018; Published: 30 December 2018

\begin{abstract}
Six series of novel isosteviol derivatives; modified in the C-19 position; were synthesized; and their antiproliferative activity was evaluated against three human cancer cell lines (HCT-116; BEL-7402; HepG2) and the human L02 normal cell line in vitro. Most of the derivatives tested here exhibited improved antiproliferative activity with high selectivity when compared with the parent compound isosteviol and the positive control drug 5-fluorouracil. Among these derivatives; compound $\mathbf{5 d}$ exhibited the most potent antiproliferative activity and commendable selectivity between cancer and normal cells. In addition; compound $\mathbf{5 d}$ inhibited the colony formation of HCT-116 cells in a concentration-dependent manner. Further studies revealed that compound $\mathbf{5 d}$ arrested the HCT-116 cell cycle in the $S$ phase; and western blot analysis demonstrated the mechanism may be correlated with a change in the expression of cyclin A; cyclin B1; and cyclin E1. Furthermore; the results of a docking study that involved placing compound $\mathbf{5 d}$ into the CDK2/cyclin A binding site revealed that its mode of action was possibly as a CDK2/cyclin A inhibitor.
\end{abstract}

Keywords: isosteviol; derivatives; antiproliferation; HCT-116

\section{Introduction}

Cancer is one of the most dangerous, fast propagating diseases of the present century. Despite the enormous advances in cancer treatment, it remains the second most common cause of death worldwide because of ineffective chemotherapy, caused by drug resistance and the inability of many drugs to differentiate between cancerous cells and normal cells [1,2]. In this background, natural products have proven the utility as the core sources of novel composition, the percentage of natural product based drugs into the market was increasing from the past years, which makes it an attractive source of cancer drug discovery [3]. Therefore, the discovery of potent and highly selective derivatives through structural modification of natural products in the development of anticancer drugs is promising.

The diterpene, isosteviol (Figure 1), bearing the distinctive tetracyclic skeleton of kaurene, exhibits wide biological activities including blood lipid control [4], anti-hypertension [5], heart-brain cell protection [6,7], blood glucose reduction [8,9] and antibacterial [10] and antiinflammation [11,12] effects [13-16]. It can be obtained as a metabolite of stevioside isolated from the leaves of the natural stevia plant [17]. Furthermore, the cytotoxic activities of isosteviol derivatives have attracted 
much attention in recent years. In the previous study, the C-15 and C-16 functionalized isosteviol derivatives, obtained by means of group-conversion or structural modification exhibited good cytotoxic activities [17-24]. In view of the low cytotoxicity of isosteviol, it is suitable for the development of highly selective anticancer drugs by chemical modification [14-16]. In addition, to the best of our knowledge, the antiproliferative mechanism of isosteviol derivatives such as cell cycle, cell apoptosis and related markers have not been reported. Therefore, in the present work, we introduced different crucial fragment in the C-19 of isosteviol in order to obtain some compounds with significantly improved antiproliferative activity and highly selectivity.

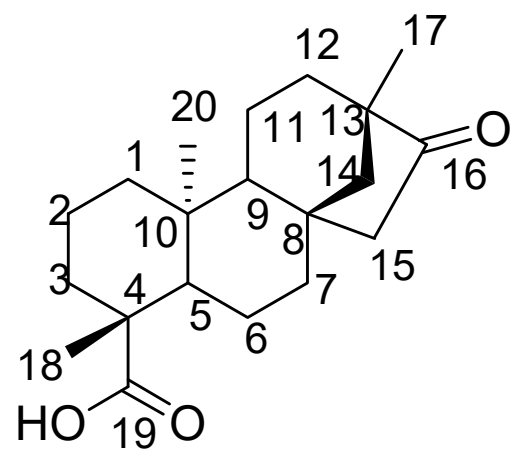

Figure 1. The chemical structure and atom number of isosteviol.

Aniline and heterocyclic fragments are common pharmacophores that display diverse biological functions, especially antiproliferative activities. Many reports have shown that introducing aniline and heterocyclic fragments in different natural products can improve their antiproliferative activity. As shown in Figure 2, compound $\mathbf{A}$ and $\mathbf{B}$ exhibited significant in vitro antiproliferative potency against the HeLa and HT24 cell lines with $\mathrm{IC}_{50}$ values of $1.63 \mu \mathrm{M}$ and $1.3 \mu \mathrm{M}$, respectively [25-28]. Amino acids are important organic compounds that have many functions in metabolism and are defined by their unique side chain. Due to their structural diversity, amino acids provide a balance between hydrophilicity and hydrophobicity which is necessary for the cell membrane solubility and permeability [29]. Our previous study investigated the structure-activity relationship of the antiproliferative effects of celastrol analogues. Compound $\mathbf{C}$ which has a tryptophan methyl ester introduced in the 20th carboxylic acid position, inhibited cell proliferation of AGS cells with an $\mathrm{IC}_{50}$ value of $0.44 \mu \mathrm{M}$ [23]. Similarly, a drug with a phosphonate introduced can display enhanced solubility and drug-like properties by regulating the distribution coefficient. Researchers have combined a variety of different natural products with these pharmacophores and found that their derivatives play an important role in antiproliferative activity [30,31]. Among them, compound D exhibited significantly improved antiproliferative activity when compared with the parent compound asiatic acid [30]. Interestingly, there are many drug discovery initiatives where triazole has been successfully conjugated with biologically active cores, showing potent antiproliferative activity. Khaybullin et al. reported that a series of isosteviol derived triazole D ring conjugates facilitated the development of potential antiproliferative agents and as the result, some derivatives showed promising antiproliferative activities against different types of cancer cell lines such as compound E [20,32].

Based on the combination principles of drugs, the aforementioned findings stimulated our interest in designing and synthesizing six series of novel isosteviol derivatives, linking these pharmacophores in the C-19 position. The antiproliferative activity of the target compounds was evaluated on human colorectal cancer (HCT-116), human hepatocellular carcinoma (BEL-7402), human liver cancer (HepG2) and human normal liver cells (L02). Furthermore, we chose the antiproliferative activity of the derivative with the strongest antiproliferative activity and investigated its possible mechanism of action. Finally, molecular docking analysis has also been performed to support the effective binding of the compound at the active site of the protein. 

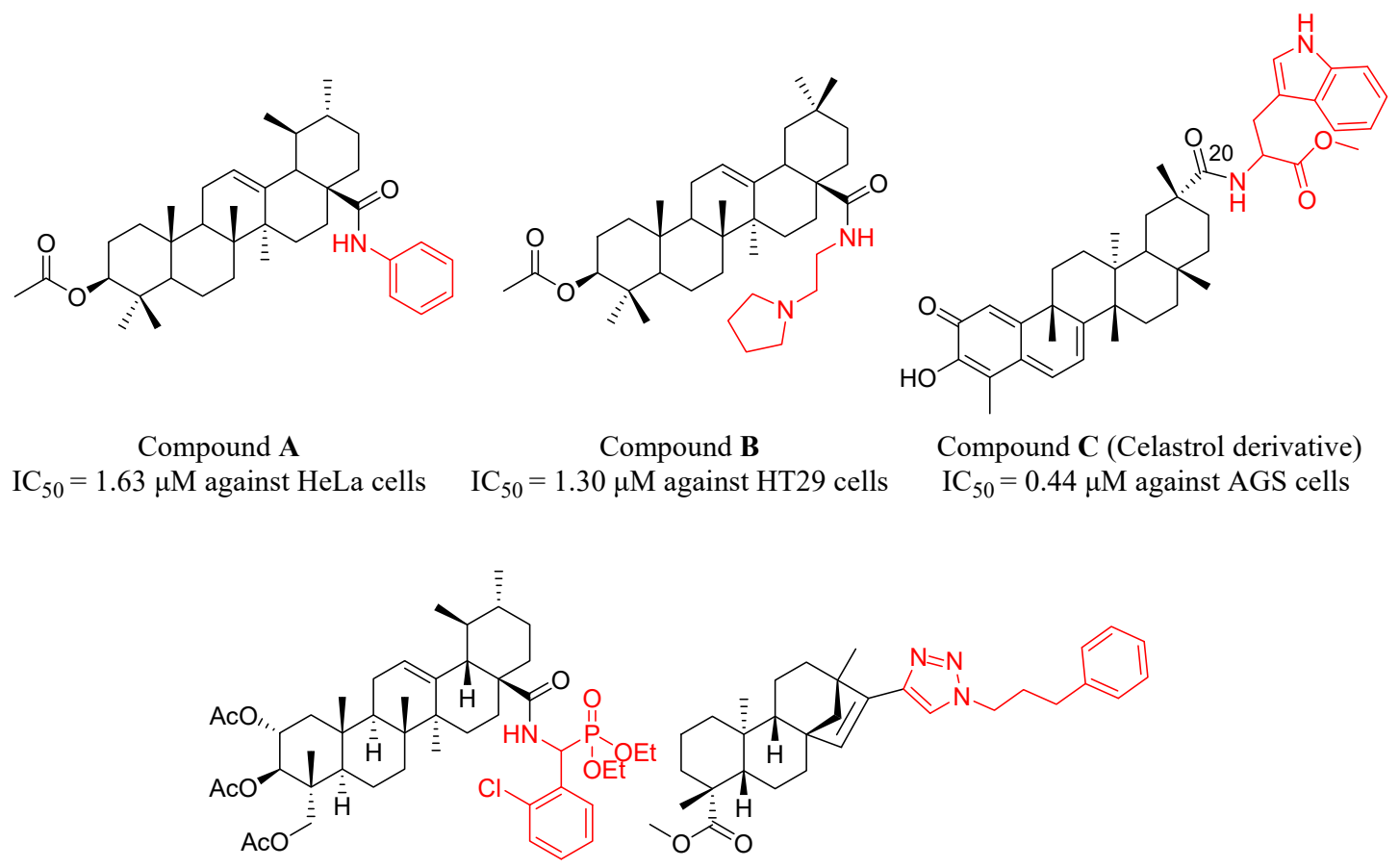

Compound $\mathbf{D}$
$\mathrm{IC}_{50}=6.59 \mu \mathrm{M}$ against $\mathrm{T} 24$ cells

Compound $\mathbf{E}$

$\mathrm{IC}_{50}=25.6 \mu \mathrm{M}$ against $\mathrm{HL}-60$ cells
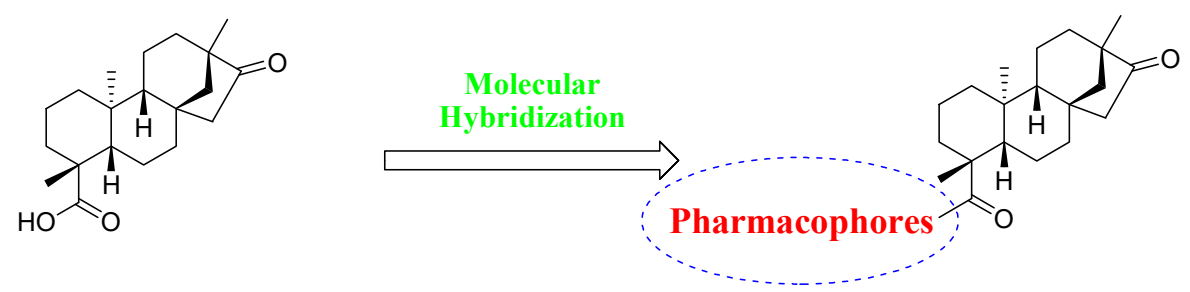

Figure 2. Design of target compounds based on the combination principles (The black part represents the parent compound and the red part represents the pharmacophore).

\section{Results and Discussion}

\subsection{Chemistry}

The synthetic procedure adopted to obtain the target compounds is shown in Scheme 1. The reaction occurred at the $\mathrm{C}-19$ position of isosteviol. Compounds $\mathbf{1 a}-\mathbf{1 c}$ are products of the reaction of isosteviol chloride with different amines at $30{ }^{\circ} \mathrm{C}$ and compounds $\mathbf{3 a}-\mathbf{3 d}$ were obtained by an amide condensation reaction with different amino acid esters, catalyzed by EDC. $\mathrm{HCl}, \mathrm{HOBt}$ and $\mathrm{Et}_{3} \mathrm{~N}$ in anhydrous $\mathrm{CHCl}_{3}$ at $60{ }^{\circ} \mathrm{C}$. The yields of $1 \mathrm{a}-1 \mathrm{c}$ were in the range of $66-71 \%$ and those of $\mathbf{3 a}-\mathbf{3} \mathbf{d}$ were in the range of $70-76 \%$. All of the other isosteviol derivatives $(\mathbf{2} \mathbf{a}-\mathbf{2 e}, \mathbf{4} \mathbf{a}-\mathbf{4} \mathbf{j}, \mathbf{5} \mathbf{a}-\mathbf{5 e}$ and 6a-6e) were generated from various chlorinated derivatives via nucleophilic substitution in good to excellent yields (78-90\%). We chose methylenecarbonyl group as a linker between isosteviol and these pharmacophores. While the carbonyl group of the linker can be used to introduce into a hydrogen bond receptor, finishing with a nucleophilic substitution reaction can make full use of starting material isosteviol and significantly increase the yield of products compared to condensation reaction. Before biological evaluation, all target compounds were characterized via ${ }^{1} \mathrm{H}-\mathrm{NMR},{ }^{13} \mathrm{C}-\mathrm{NMR}$ and high-resolution mass spectrometry. $1 \mathrm{H}$ and 13C-NMR spectra of these compounds are available in the supplementary materials. 


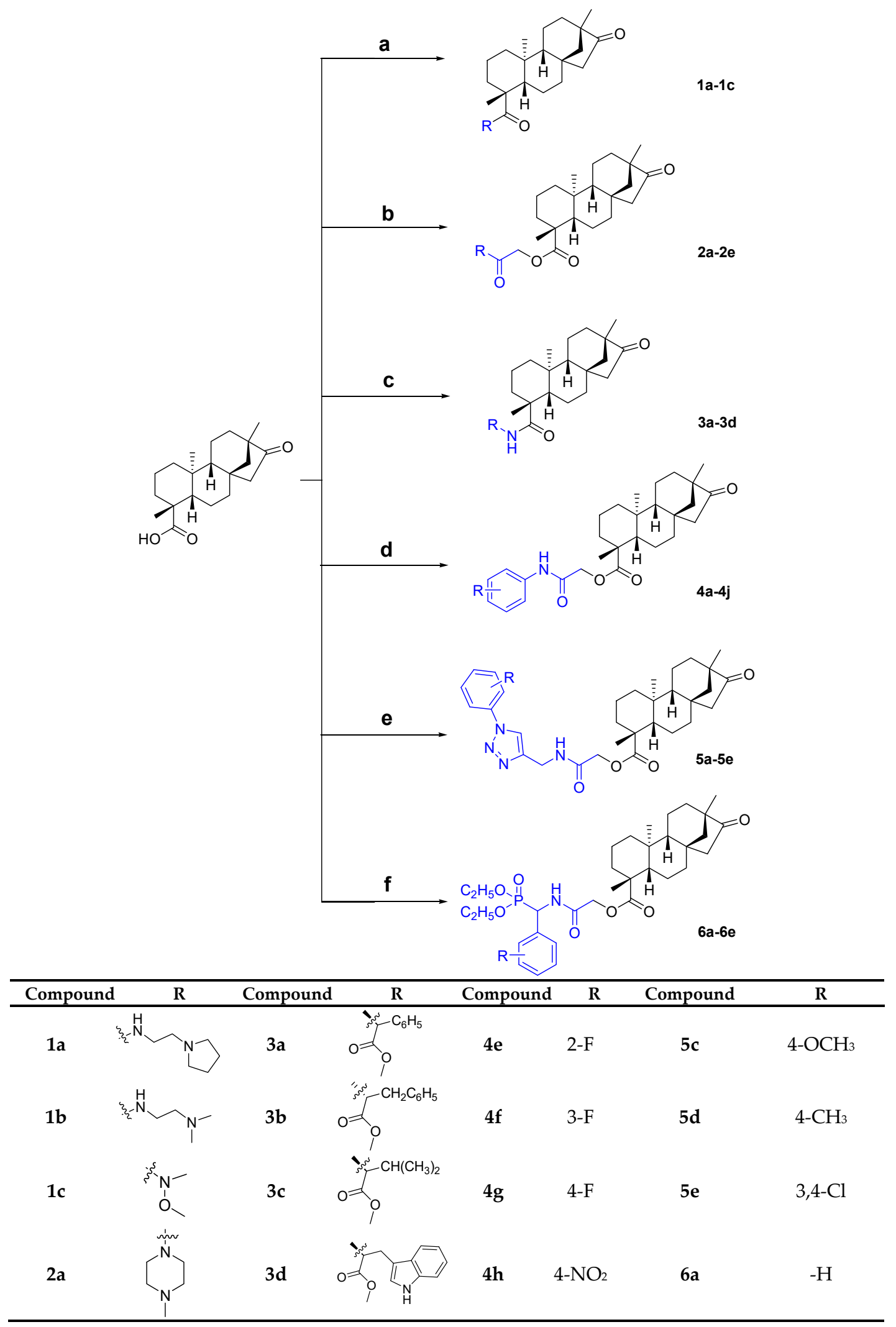

Scheme 1. Cont. 


\begin{tabular}{|c|c|c|c|c|c|c|}
\hline $2 b$ & $4 a$ & $-\mathrm{H}$ & $4 \mathbf{i}$ & $\begin{array}{c}4-\mathrm{OCH} \\
3\end{array}$ & $6 b$ & $4-\mathrm{Cl}$ \\
\hline $2 c$ & $4 b$ & $2-\mathrm{Cl}$ & $4 \mathbf{j}$ & $\begin{array}{c}2,5-\mathrm{OC} \\
\mathrm{H}_{3}\end{array}$ & $6 c$ & $4-\mathrm{OCH}_{3}$ \\
\hline $2 d$ & $4 c$ & $3-\mathrm{Cl}$ & $5 a$ & $-\mathrm{H}$ & $6 d$ & $4-\mathrm{CH}_{3}$ \\
\hline $2 e$ & $4 d$ & $4-\mathrm{Cl}$ & $5 b$ & $4-\mathrm{Cl}$ & $6 e$ & $3,4-\mathrm{Cl}$ \\
\hline
\end{tabular}

Scheme 1. Reagents and conditions: (a) (i) oxalyl chloride, $\mathrm{CHCl}_{3}, 60{ }^{\circ} \mathrm{C}$; (ii) IIa-IIe, $\mathrm{Et}_{3} \mathrm{~N}, \mathrm{CH}_{2} \mathrm{Cl}_{2}, 30$ ${ }^{\circ} \mathrm{C}$. (b) different heterocyclic chloroacetamides, $\mathrm{K}_{2} \mathrm{CO}_{3}, \mathrm{CH}_{3} \mathrm{CN}, 80^{\circ} \mathrm{C}$. (c) different amino acid esters, $\mathrm{EDC} \cdot \mathrm{HCl}, \mathrm{HOBt}, \mathrm{Et}_{3} \mathrm{~N}, \mathrm{CHCl}_{3}, 60^{\circ} \mathrm{C}$. (d) IVa-IVj, $\mathrm{K}_{2} \mathrm{CO}_{3}, \mathrm{CH}_{3} \mathrm{CN}, 80^{\circ} \mathrm{C}$. (e) $\mathrm{Va}-\mathrm{Ve}, \mathrm{K}_{2} \mathrm{CO}_{3}, \mathrm{CH}_{3} \mathrm{CN}$, $80{ }^{\circ} \mathrm{C}$. (f) VIa-VIe, $\mathrm{K}_{2} \mathrm{CO}_{3}, \mathrm{CH}_{3} \mathrm{CN}, 80{ }^{\circ} \mathrm{C}$.

\subsection{In Vitro Antiproliferative Activity}

As shown in Table 1, thirty-two target compounds were evaluated for their antiproliferative activities in vitro against HCT-116, BEL-7402 and HepG2 cell lines. The activity of isosteviol was used as reference. With the exception of compounds $\mathbf{1 c}, \mathbf{2 b}, \mathbf{2 c}, \mathbf{3 d}, \mathbf{4 b}, \mathbf{4 c}, \mathbf{4 e}, \mathbf{4} \mathbf{i}$ and $\mathbf{4 j}$, all target compounds exhibited stronger antiproliferative activity against three different human cancer cell lines than the lead compound isosteviol at $100 \mu \mathrm{M}$. However, some compounds lost their antiproliferative activity at lower concentrations and half of the target compounds had a lower $\mathrm{IC}_{50}$ value $(<100 \mu \mathrm{M})$ than the lead compound isosteviol against the cancer cell lines.

Table 1. The antiproliferative activity of compounds (\% Growth Inhibition at $100 \mu \mathrm{M})$.

\begin{tabular}{cccc}
\hline \multirow{2}{*}{ Compound } & \multicolumn{3}{c}{ \% Growth Inhibition at $\mathbf{1 0 0} \boldsymbol{\mu M}$} \\
\cline { 2 - 4 } & HCT-116 & BEL-7402 & HepG2 \\
\hline $\mathbf{1 a}$ & $65.22 \pm 2.52$ & $87.10 \pm 2.37$ & $66.02 \pm 1.33$ \\
$\mathbf{1 b}$ & $76.61 \pm 1.78$ & $88.51 \pm 2.02$ & $56.96 \pm 2.35$ \\
$\mathbf{1 c}$ & $\mathrm{NA}$ & $31.34 \pm 1.22$ & $\mathrm{NA}$ \\
$\mathbf{2 a}$ & $62.06 \pm 1.02$ & $65.04 \pm 2.62$ & $40.61 \pm 0.70$ \\
$\mathbf{2 b}$ & $60.37 \pm 1.69$ & $64.36 \pm 1.66$ & $\mathrm{NA}$ \\
$\mathbf{2 c}$ & $15.71 \pm 0.61$ & $40.46 \pm 0.87$ & $\mathrm{NA}$ \\
$\mathbf{2 d}$ & $75.37 \pm 1.06$ & $70.86 \pm 1.05$ & $70.63 \pm 0.89$ \\
$\mathbf{2} \mathbf{c}$ & $85.61 \pm 0.96$ & $64.87 \pm 1.01$ & $50.36 \pm 0.57$ \\
$\mathbf{3 a}$ & $86.26 \pm 0.59$ & $80.01 \pm 0.95$ & $75.25 \pm 0.56$ \\
$\mathbf{3 b}$ & $70.75 \pm 0.98$ & $61.76 \pm 0.96$ & $81.15 \pm 2.66$ \\
$\mathbf{3 c}$ & $54.71 \pm 0.59$ & $66.62 \pm 1.90$ & $23.87 \pm 0.85$ \\
$\mathbf{3 d}$ & $19.66 \pm 1.11$ & $35.78 \pm 2.37$ & $\mathrm{NA}$ \\
$\mathbf{4 a}$ & $60.44 \pm 3.11$ & $50.78 \pm 2.31$ & $31.18 \pm 1.19$ \\
$\mathbf{4 b}$ & $\mathrm{NA}$ & $\mathrm{NA}$ & $\mathrm{NA}$ \\
$\mathbf{4 c}$ & $62.34 \pm 3.55$ & $35.68 \pm 2.56$ & $\mathrm{NA}$ \\
$\mathbf{4 d}$ & $56.85 \pm 2.35$ & $52.92 \pm 2.11$ & $31.91 \pm 1.31$ \\
$\mathbf{4 e}$ & $27.87 \pm 0.44$ & $38.66 \pm 1.52$ & $\mathrm{NA}$ \\
$\mathbf{4 f}$ & $68.74 \pm 2.67$ & $54.58 \pm 3.11$ & $49.12 \pm 0.44$ \\
$\mathbf{4 g}$ & $65.64 \pm 3.01$ & $62.96 \pm 2.13$ & $39.11 \pm 1.13$ \\
$\mathbf{4 h}$ & $55.35 \pm 2.55$ & $71.38 \pm 2.36$ & $76.46 \pm 1.00$ \\
$\mathbf{4 i}$ & $53.14 \pm 2.56$ & $45.62 \pm 1.47$ & $\mathrm{NA}$ \\
$\mathbf{4 j}$ & $\mathrm{NA}$ & $31.30 \pm 1.76$ & $\mathrm{NA}$ \\
\hline
\end{tabular}


Table 1. Cont.

\begin{tabular}{cccc}
\hline \multirow{2}{*}{ Compound } & \multicolumn{3}{c}{ \% Growth Inhibition at $\mathbf{1 0 0} \boldsymbol{\mu M}$} \\
\cline { 2 - 4 } & HCT-116 & BEL-7402 & HepG2 \\
\hline $\mathbf{5 a}$ & $81.87 \pm 2.55$ & $90.02 \pm 1.92$ & $87.03 \pm 1.06$ \\
$\mathbf{5 b}$ & $85.60 \pm 1.34$ & $90.49 \pm 1.04$ & $82.10 \pm 1.82$ \\
$\mathbf{5} \mathbf{c}$ & $84.64 \pm 1.55$ & $75.56 \pm 1.76$ & $82.85 \pm 2.02$ \\
$\mathbf{5 d}$ & $84.61 \pm 0.96$ & $86.46 \pm 0.87$ & $82.77 \pm 0.86$ \\
$\mathbf{5 e}$ & $71.14 \pm 0.65$ & $67.96 \pm 1.17$ & $66.10 \pm 0.97$ \\
$\mathbf{6 a}$ & $50.05 \pm 2.27$ & $33.66 \pm 0.91$ & $28.02 \pm 0.99$ \\
$\mathbf{6 b}$ & $50.34 \pm 2.31$ & $50.36 \pm 1.63$ & $40.22 \pm 2.56$ \\
$\mathbf{6 c}$ & $74.07 \pm 2.45$ & $50.87 \pm 2.68$ & $41.40 \pm 1.86$ \\
$\mathbf{6 d}$ & $76.63 \pm 2.33$ & $51.46 \pm 0.68$ & $80.64 \pm 0.76$ \\
$\mathbf{6 e}$ & $43.45 \pm 0.56$ & $49.88 \pm 1.26$ & $39.47 \pm 1.37$ \\
Isosteviol & $34.09 \pm 1.89$ & $28.04 \pm 1.79$ & $11.79 \pm 0.88$ \\
\hline
\end{tabular}

NA: antiproliferative activity $<10 \% . \%$ Growth Inhibition are presented as the mean \pm SD (standard error of the mean) from three separated experiment.

As shown in Table 2, all of these compounds showed moderate to significant activity against all three cancer cell lines, improved potency up to one-two digits $\mu \mathrm{M}$ compared with isosteviol. Among the compounds $\mathbf{1} \mathbf{a}-\mathbf{1} \mathbf{c}$, which react with amines compounds, only compound $\mathbf{1} \mathbf{b}$ exhibited slightly higher antiproliferative activity against the HCT-116 cell line $\left(\mathrm{IC}_{50}=24.04 \pm 1.20 \mu \mathrm{M}\right)$ compared with the positive-control drug 5-FU. Compounds $\mathbf{2 a - 2 e}$ are products of a reaction between isosteviol and heterocyclic chloroacetamides. In this series of compounds, compound $\mathbf{2 d}$ exhibited higher antiproliferative activity against the HCT-116 and HepG2 cell lines ( $\mathrm{IC}_{50}$ value of $18.18 \pm 1.26 \mu \mathrm{M}$ and $11.05 \pm 0.55$, respectively) and compound $2 \mathrm{e}$ exhibited higher antiproliferative activity against the BEL-7402 and HepG2 cell lines ( $\mathrm{IC}_{50}$ value of $13.22 \pm 0.32 \mu \mathrm{M}$ and $20.51 \pm 0.46$, respectively) when compared with 5-FU. Compounds 3a-3d were generated from amino acid esters. Only compound $3 \mathbf{b}$, which has a D-phenylalanine methyl ester introduced in the C-19 position, displayed similar antiproliferative activity against the three cancer cell lines $\left(\mathrm{IC}_{50}=22.78 \pm 0.81 \mu \mathrm{M}\right.$ against HCT-116 cells, $\mathrm{IC}_{50}=36.49 \pm 0.67 \mu \mathrm{M}$ against BEL-7402 cells and $\mathrm{IC}_{50}=24.40 \pm 1.75 \mu \mathrm{M}$ against HepG2 cells). Compounds $4 \mathbf{a}-\mathbf{4} \mathbf{j}$ are products of a reaction between isosteviol and various chloroacetanilides. Among them, compound $4 \mathrm{f}$ showed selective cytotoxic effects against the HCT-116 cell line, with an $\mathrm{IC}_{50}$ value of $17.22 \pm 0.43 \mu \mathrm{M}$, while compound $4 \mathrm{~h}$ displayed better antiproliferative activity against the BEL-7402 and HepG2 cell lines ( $\mathrm{IC}_{50}=12.14 \pm 0.12 \mu \mathrm{M}$ and $\mathrm{IC}_{50}=14.11 \pm 0.27 \mu \mathrm{M}$, respectively). Thus, compounds with an electron-withdrawing group $\left(-\mathrm{F},-\mathrm{NO}_{2}\right)$ at the phenyl moiety displayed better antiproliferative activity. Compounds 5a-5e have different phenyl 1,2,3-triazole chloroacetamides compounds substituted. All of these compounds showed considerably higher antiproliferative activity against the HCT-116 and HepG2 cell lines. Perhaps the triazole acts as a hydrogen bond acceptor and binds to some key enzymes involved in cancer cell metabolism, inhibiting their expression. Compound $\mathbf{5 a}$ and $\mathbf{5 b}$ exhibited significant in vitro antiproliferative potency against the HepG2 and HCT-116 cell lines with $\mathrm{IC}_{50}$ values of $9.87 \pm 0.13 \mu \mathrm{M}$ and $7.44 \pm 0.37 \mu \mathrm{M}$, respectively. Compound $\mathbf{5 d}$, which has a methyl group introduced at the para position of the benzene ring, had the strongest antiproliferative activity among all the target compounds ( $\mathrm{IC}_{50}$ value of $5.38 \pm 0.26 \mu \mathrm{M}, 15.91 \pm 0.41 \mu \mathrm{M}$ and 8.92 $\pm 0.44 \mu \mathrm{M}$ against HCT-116, BEL-7402 and HepG2 cell lines, respectively). It was 4.6-fold (against HCT-116 cells), 1.3-fold (against BEL-7402 cells) and 2.6-fold (against HepG2 cells) more active than 5-FU. Also, it was 18.6-fold (against HCT-116 cells), 6.3-fold (against BEL-7402 cells) and 11.2-fold (against HepG2 cells) more active than lead compound isosteviol at least. Compounds 6a-6e, were generated by reactions with different phosphonic acid [[(chloroacetyl) amino] phenylmethyl]-diethyl esters. Compound $\mathbf{6 c}$ showed higher antiproliferative activity against the HCT-116 cell line $\left(\mathrm{IC}_{50}=\right.$ $15.15 \pm 0.11 \mu \mathrm{M})$ and compound $\mathbf{6} \mathbf{d}$ showed better antiproliferative activity against the HCT-116 and HepG2 cell lines $\left(\mathrm{IC}_{50}=18.70 \pm 0.17\right.$ and $13.19 \pm 0.86 \mu \mathrm{M}$, respectively). However, compounds $\mathbf{6 a}, \mathbf{6 b}$ 
and $6 e$ lost their antiproliferative activity. It seems that the antiproliferative ability was enhanced after the introduction of electron-donating groups to the para position of the benzene ring.

It is worth mentioning that all the target compounds exhibited low cytotoxic activities against human normal liver cells (L02), with remarkable selectivity $\left(\mathrm{IC}_{50}>100 \mu \mathrm{M}\right)$, which supported the rationale of the drug design. Above all, we chose to investigate the mechanism of action for compound $\mathbf{5} \mathbf{d}$ because it had the strongest antiproliferative activity against HCT-116 cell line.

Table 2. $\mathrm{IC}_{50}$ values $(\mu \mathrm{M})$ of several active compounds.

\begin{tabular}{ccccc}
\hline \multirow{2}{*}{ Compound } & \multicolumn{4}{c}{ IC $_{\mathbf{5 0}}$ Values $(\boldsymbol{\mu M})^{\mathbf{a}}$} \\
\cline { 2 - 5 } & HCT-116 & BEL-7402 & HepG2 & L02 \\
\hline $\mathbf{1 b}$ & $24.04 \pm 1.20$ & $>100$ & $>100$ & $>100$ \\
$\mathbf{2 b}$ & $30.71 \pm 1.98$ & $>100$ & $>100$ & $>100$ \\
$\mathbf{2 d}$ & $18.18 \pm 1.26$ & $52.98 \pm 1.97$ & $11.05 \pm 0.55$ & $>100$ \\
$\mathbf{2} \mathbf{e}$ & $>100$ & $13.22 \pm 0.32$ & $20.51 \pm 0.46$ & $>100$ \\
$\mathbf{3 a}$ & $40.41 \pm 0.97$ & $>100$ & $>100$ & $>100$ \\
$\mathbf{3 b}$ & $22.78 \pm 0.81$ & $36.49 \pm 0.67$ & $24.40 \pm 1.75$ & $>100$ \\
$\mathbf{4 a}$ & $56.56 \pm 1.56$ & $>100$ & $>100$ & $>100$ \\
$\mathbf{4 f}$ & $17.22 \pm 0.43$ & $>100$ & $>100$ & $>100$ \\
$\mathbf{4 h}$ & $>100$ & $12.14 \pm 0.12$ & $14.11 \pm 0.27$ & $>100$ \\
$\mathbf{5 a}$ & $14.63 \pm 0.51$ & $27.10 \pm 0.87$ & $9.87 \pm 0.13$ & $>100$ \\
$\mathbf{5 b}$ & $7.44 \pm 0.37$ & $22.50 \pm 0.58$ & $11.67 \pm 0.23$ & $>100$ \\
$\mathbf{5 c}$ & $14.40 \pm 1.31$ & $>100$ & $12.27 \pm 0.77$ & $>100$ \\
$\mathbf{5 d}$ & $5.38 \pm 0.26$ & $15.91 \pm 0.41$ & $8.92 \pm 0.44$ & $>100$ \\
$\mathbf{5 e}$ & $14.32 \pm 0.15$ & $>100$ & $12.82 \pm 0.09$ & $>100$ \\
$\mathbf{6 c}$ & $15.15 \pm 0.11$ & $92.61 \pm 1.96$ & $>100$ & $>100$ \\
$\mathbf{6 d}$ & $18.70 \pm 0.17$ & $60.93 \pm 1.37$ & $13.19 \pm 0.86$ & $>100$ \\
Isosteviol & $>100$ & $>100$ & $>100$ & $>100$ \\
$\mathbf{5 - F U}$ & $24.80 \pm 2.08$ & $21.30 \pm 2.43$ & $23.45 \pm 0.37$ & $19.12 \pm 1.01$ \\
\hline
\end{tabular}

${ }^{a} \mathrm{IC}_{50}$ : concentration that inhibits $50 \%$ of cell growth. The values are presented as the mean $\pm \mathrm{SD}$ (standard error of the mean) from three separated experiments.

\subsection{Selective Inhibition of Cancer Cell Growth by Compounds $\mathbf{5 d}$}

Lack of selective cytotoxicity is the main factor that restricts the conventional chemotherapeutic agents $[29,33]$. Thus, to evaluate the selective antiproliferative activity of the compound $5 \mathbf{d}$, the selectivity index (SI) between cancer and normal cells was calculated and the results are summarized in Table 3. The SI was calculated by the dividing the $\mathrm{IC}_{50}$ values in normal cells by the $\mathrm{IC}_{50}$ values in cancer cells. 5-FU had similar effects and toxic doses, with SI values of 0.77 (HCT-116), 0.90 (BEL-7402) and 0.82 (HepG2), respectively, indicating that both normal cells and cancer cells would be killed. Whereas, compound 5d exhibited a 38.17-fold, 11.24-fold and 22.01-fold higher selectivity for HCT-116, BEL-7402 and HepG2 cells, respectively. It means that $\mathbf{5 d}$ has much better therapeutic activity and specificity than 5-FU.

Table 3. In vitro antiproliferative activities of compound $\mathbf{5 d}$ against normal cell line (L02).

\begin{tabular}{ccccc}
\hline \multirow{2}{*}{ Compound } & $\left(\mathrm{IC}_{\mathbf{5 0}}, \boldsymbol{\mu M}\right)$ & \multicolumn{3}{c}{ Selectivity Index a } \\
\cline { 2 - 5 } & L02 & HCT-116 & BEL-7402 & HepG2 \\
\hline \multirow{2}{*}{$\mathbf{d}$} & $161.04 \pm 1.96$ & 29.93 & 10.12 & 18.05 \\
5-FU & $19.12 \pm 1.01$ & 0.77 & 0.90 & 0.82 \\
\hline
\end{tabular}

${ }^{a}$ SI: selective index $\left(\mathrm{IC}_{50}\right.$ on normal cells $/ \mathrm{IC}_{50}$ on cancer cells). 


\subsection{Compound 5d Inhibited HCT-116 Cells Colony Formation}

Colony formation represents the malignant potential, which is a basic characteristic of cancer cells. Colony formation assay is used to test cells for their ability to form colonies and undergo unlimited division [34]. The combined results of three independent experiments are depicted in Figure 3. The exposure of HCT-116 cells to compound $\mathbf{5 d}$ resulted in a significant suppression of colony formation in a concentration-dependent manner. It led to fewer and smaller colonies compared to the control with an inhibition rate of $84 \%$ at $15 \mu \mathrm{M}$ and colony formation was almost completely suppressed. These results demonstrate that compound $\mathbf{5 d}$ can significantly inhibit the proliferation of HCT-116 cells.

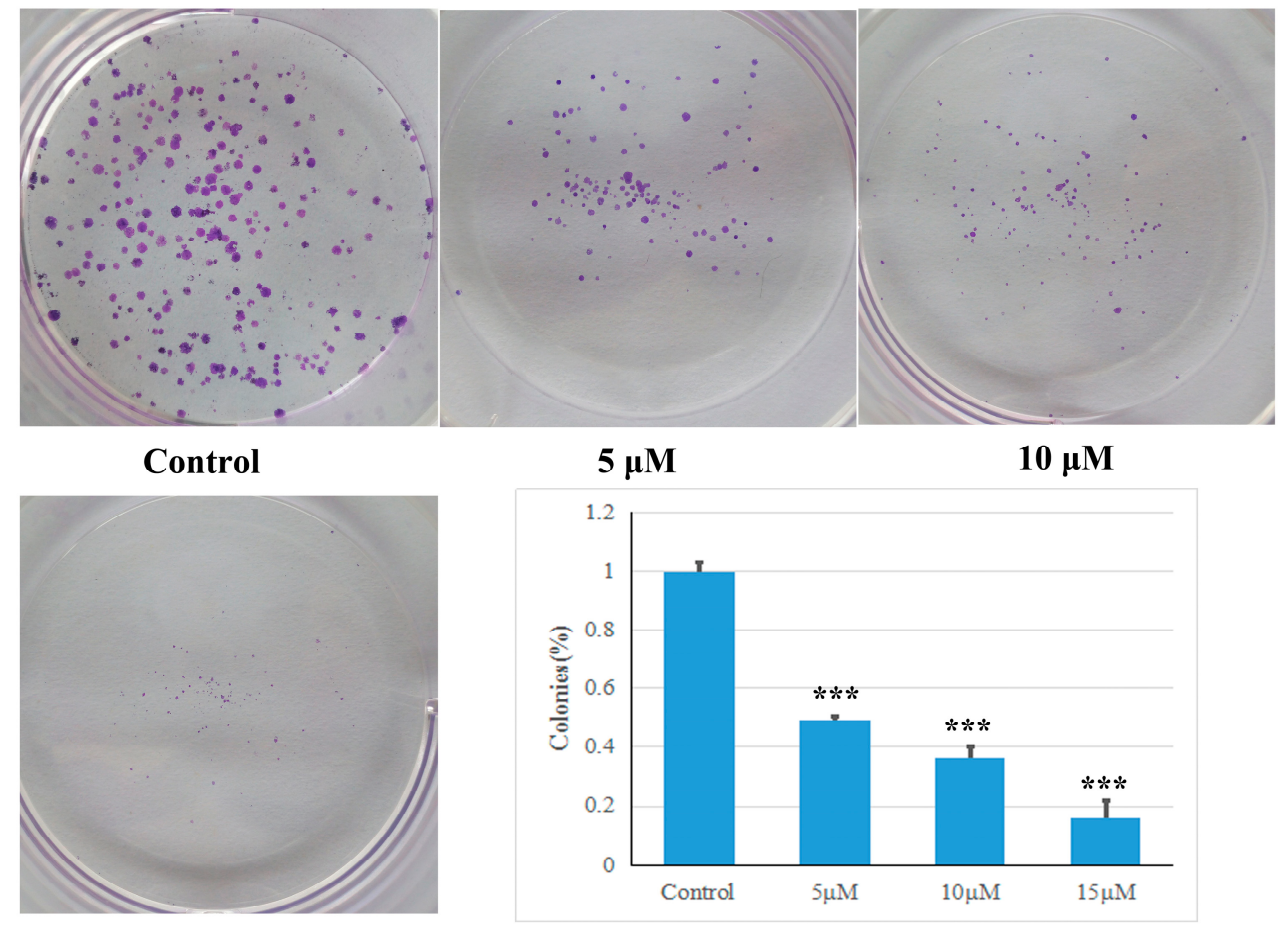

$15 \mu \mathrm{M}$

Figure 3. The colony formation of HCT-116 cells after treatment with different concentration $(5,10$ and $15 \mu \mathrm{M}$ ) of compound $\mathbf{5 d}$ for 7 days; The rate of inhibition induced by compound $\mathbf{5} \mathbf{d}$ was expressed as the mean \pm SD of three independent experiments, ${ }^{* * *} p<0.001$ vs control group (untreated cells); The clonogenicity assay was quantified using Image $J$ software.

\subsection{Analysis for Cell Cycle and Apoptosis by Flow Cytometry}

Cell cycle dysregulation resulting in mitogenic signaling and leading to uncontrolled proliferation is one of the hallmarks of cancer. Also, inducing apoptosis is one of the protective mechanisms used against cancer initiation and progression, which is a significant goal of anticancer therapy. Many cytotoxic compounds exert their antiproliferative effect by the arrest of the cell cycle at a particular cell cycle checkpoint, the induction of apoptosis or by a combination of these two effects. This type of mechanism is considered to be an effective anticancer strategy $[35,36]$. Therefore, in order to identify whether compound 5d inhibited cell proliferation through cell cycle arrest or apoptosis, we assayed its ability to trigger cell cycle arrest and apoptosis in HCT-116 cells by flow cytometry. As shown in Figure 4A), the proportion of cells in the G1 phase decreased from $70.67 \%$ in the control to $51.67 \%$ and $41.32 \%$ when treated with 5 and $15 \mu \mathrm{M}$ compound $\mathbf{5 d}$, respectively and the proportion of cells in the $\mathrm{S}$ phase dramatically increased in a concentration-dependent manner, from $18.64 \%$ (control) to $25.70 \%$ (5 $\mu \mathrm{M})$ and $42.31 \%(15 \mu \mathrm{M})$, this implies that the cell is unable to duplicate its DNA. The results indicate that compound $\mathbf{5 d}$ arrests cells in the $S$ phase of the cell cycle. 
To determine whether antiproliferation caused by compound $\mathbf{5 d}$ was due to increasing of apoptosis, annexin V-FITC/propidium iodide assay was used to investigate apoptosis. As shown in Figure $4 \mathrm{~B}$ ), at $5 \mu \mathrm{M}$, the percentage of total apoptotic cells (right quadrants, UR + LR) increased inconsiderably, from $5.98 \%$ (control) to $7.67 \%$. After increasing the concentration of the drug to $15 \mu \mathrm{M}$, the percentage of total apoptotic cells increased to $24.94 \%$. However, we have found that the number of dead cells (UL) also increased from $8.84 \%$ (control) to $49.22 \%(15 \mu \mathrm{M})$. It is likely that compound $\mathbf{5 d}$ causes cell death by inducing apoptosis in combination with other ways. These results indicate that compound $\mathbf{5 d}$ have a weaker influence on cell apoptosis.
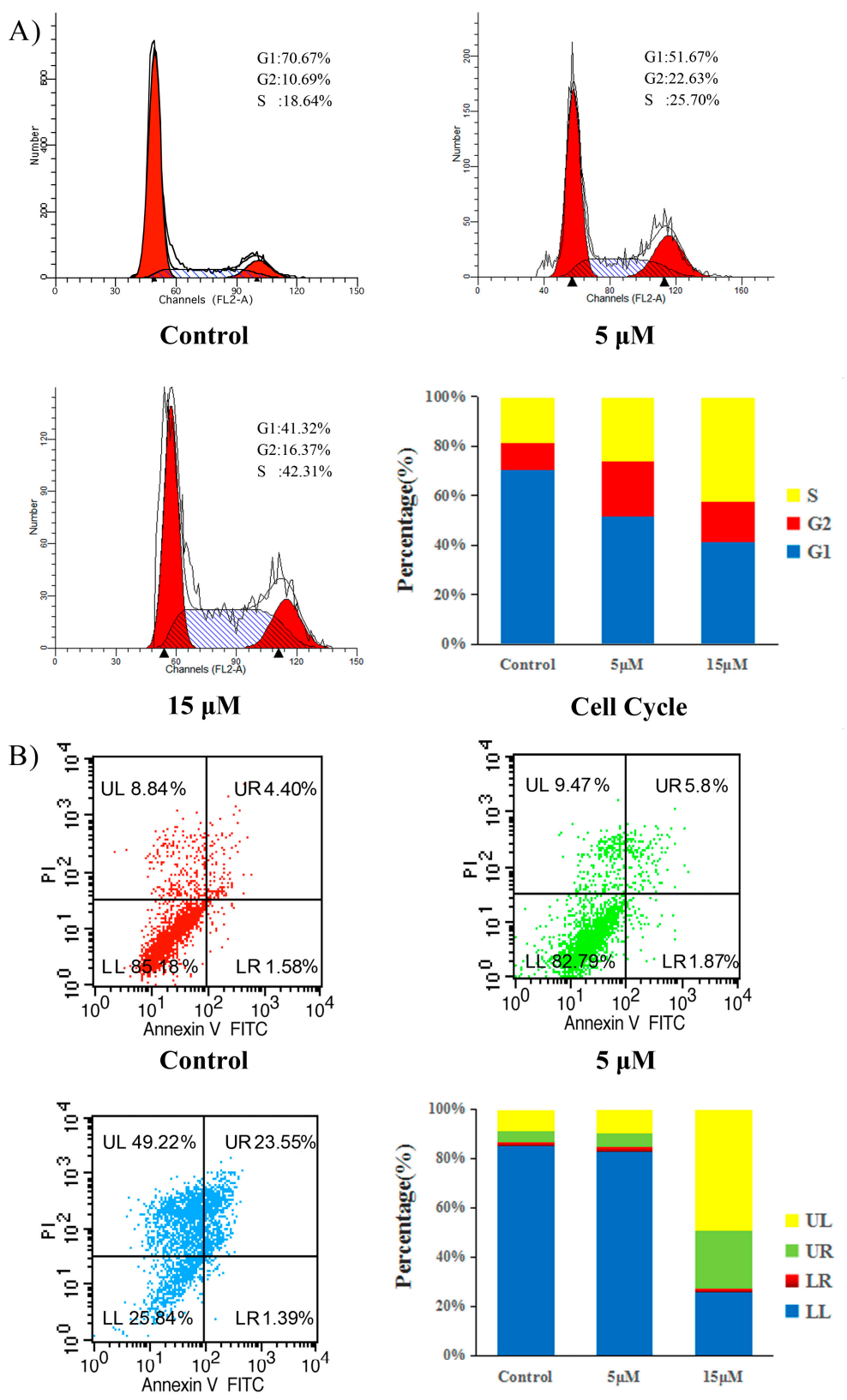

$15 \mu \mathrm{M}$

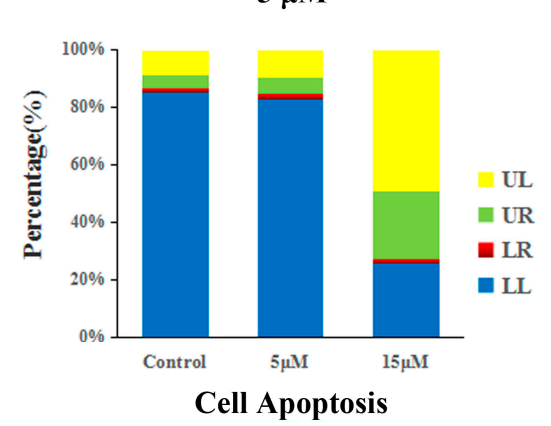

Figure 4. (A): Flow cytometry analyses of cell cycle distribution of HCT-116 cells after treatment of compound $5 \mathbf{d}(5$ and $15 \mu \mathrm{M})$ and no treatment (Ctrl) as a reference for $24 \mathrm{~h}$; (B): Apoptosis induction in HCT-116 cells after treatment of compound $5 \mathbf{d}(5$ and $15 \mu \mathrm{M})$ and no treatment (Ctrl) as a reference for $24 \mathrm{~h}$. 


\subsection{Western Blot Analysis}

It is known that cell proliferation is generally regulated by controlling cell cycle progression through inhibition or promotion of activities of cyclins and their associated proteins. Cyclins play a significant role in cell cycle progression by activation of ATP binding site [37]. Cyclin E helps in the $\mathrm{Rb} / \mathrm{E} 2 \mathrm{~F}$ transcription via formation of a complex with the CDK2 and controls G1 phase [38]. Cyclin A forms a complex with CDK2 and helps in the regulation of S phase [37]. Cyclin B is also called as maturation or mitosis promoting factor as it forms complex with CDK1 and controls the M phase of the cell cycle [39]. Analysis for cell cycle by flow cytometry confirmed that compound $\mathbf{5 d}$ induced arrest in S phase of the HCT-116 cells. However, it had a weaker influence on cell apoptosis. Therefore, the further research on apoptosis-related proteins was abandoned. Since entry into the $S$ phase in the cell cycle requires the accumulation of cell cycle activation-related cyclins, we further examined the effect of compound $\mathbf{5 d}$ on cell cycle regulating proteins such as cyclin A, cyclin B1 and cyclin E1 to determine whether the decreased cell proliferation by $\mathbf{5 d}$ involved these proteins. As shown in Figure 5, in a concentration-dependent manner, compound $\mathbf{5 d}$ decreased cyclin A and cyclin E1 protein levels, while increasing the level of cyclin B1. It has been reported that expression of cyclin B1 is increased by exposure to anticancer agents $[40,41]$. Hence, these results suggest that the up-regulation of cyclin B1 and down-regulation of cyclins $\mathrm{A}$ and $\mathrm{E} 1$ are related to the decrease in cell proliferation and $\mathrm{S}$ phase arrest by $\mathbf{5 d}$ treatment on HCT-116 cells.

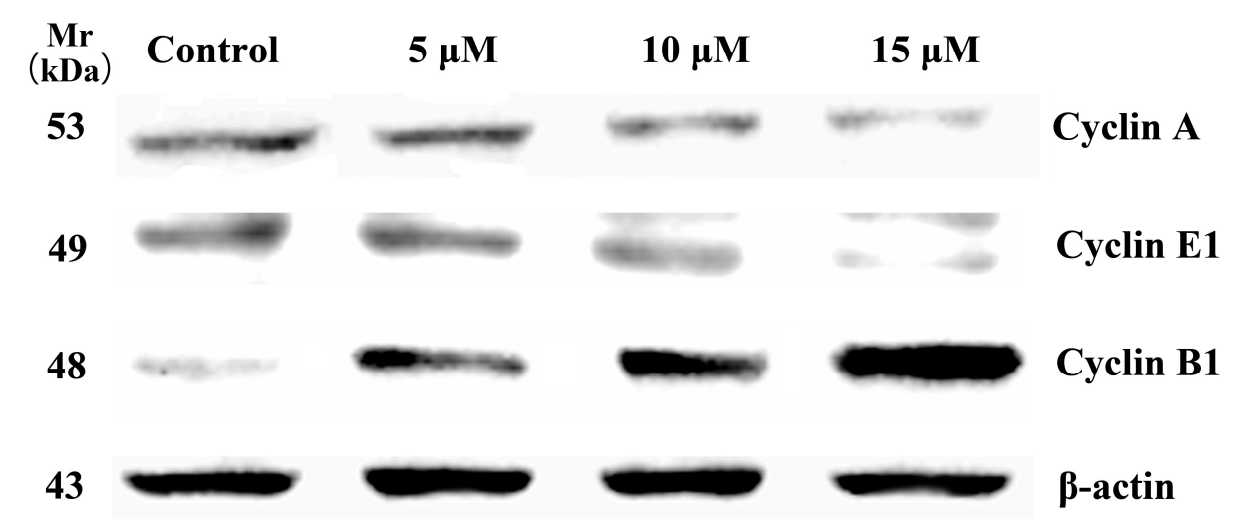

Figure 5. Western blot analysis: Effects of Cyclin A, Cyclin E1 and Cyclin B1 in HCT-116 cells after $24 \mathrm{~h}$ treatment with compound $\mathbf{5 d}$ at 5, 10 and $15 \mu \mathrm{M}$. $\beta$-actin served as an internal control.

\subsection{Molecular Docking Analysis}

Our cell cycle study revealed compound $\mathbf{5 d}$ induced arrest in S phase of the HCT-116 cells and western blot analysis demonstrated the mechanism of action may be correlated with down-regulation of cyclin A, in addition, cyclin A and CDK2 form a complex that plays a key role in the regulation of the $\mathrm{S}$ phase. Therefore, in order to better understand the potency of compound $\mathbf{5 d}$ and to gain further understanding of the probable binding model, molecular docking studies with CDK2/cyclin A (PDB ID: 3my5) were performed. The studies were performed as a crucial step towards understanding the specific position of interaction between compound $\mathbf{5 d}$ and CDK2/cyclin A complex [42]. The docking results revealed that compound $\mathbf{5} \mathbf{d}$ was held in the active pocket by a combination of various hydrogen bonds and alkyl interactions with CDK2/cyclin A (Figure 6). The carbonyl group of isosteviol interacted with the $-\mathrm{NH}_{2}$ group of Lys-A56 via hydrogen bond, while the carbonyl group of 1,2,3-triazole chloroacetamides interacted with the -NH- moiety of Lys-A56 via hydrogen bond, which supported the preceding drug design. Meanwhile, the 1,2,3-triazole moiety formed one pi-donor hydrogen bond with Gly-A1 residue, as well as the methylenecarbonyl group and the carbonyl group of C-19 formed three carbon hydrogen bond with Ile-C70, Val-C69 and Lys-B300 amino acids. Additionally, the methyl group at the para position of the benzene ring formed a favorable alkyl interaction with Val-D301 residue. It was also observed that the B and C ring of isosteviol showed alkyl 
interaction with amino acid residue Ala-B303. The CDOCKER interaction energy score was 41.3422. These indicate that compound $\mathbf{5 d}$ has a strong binding affinity for the CDK2/cyclin A complex and may play a crucial role in inhibiting its activity.
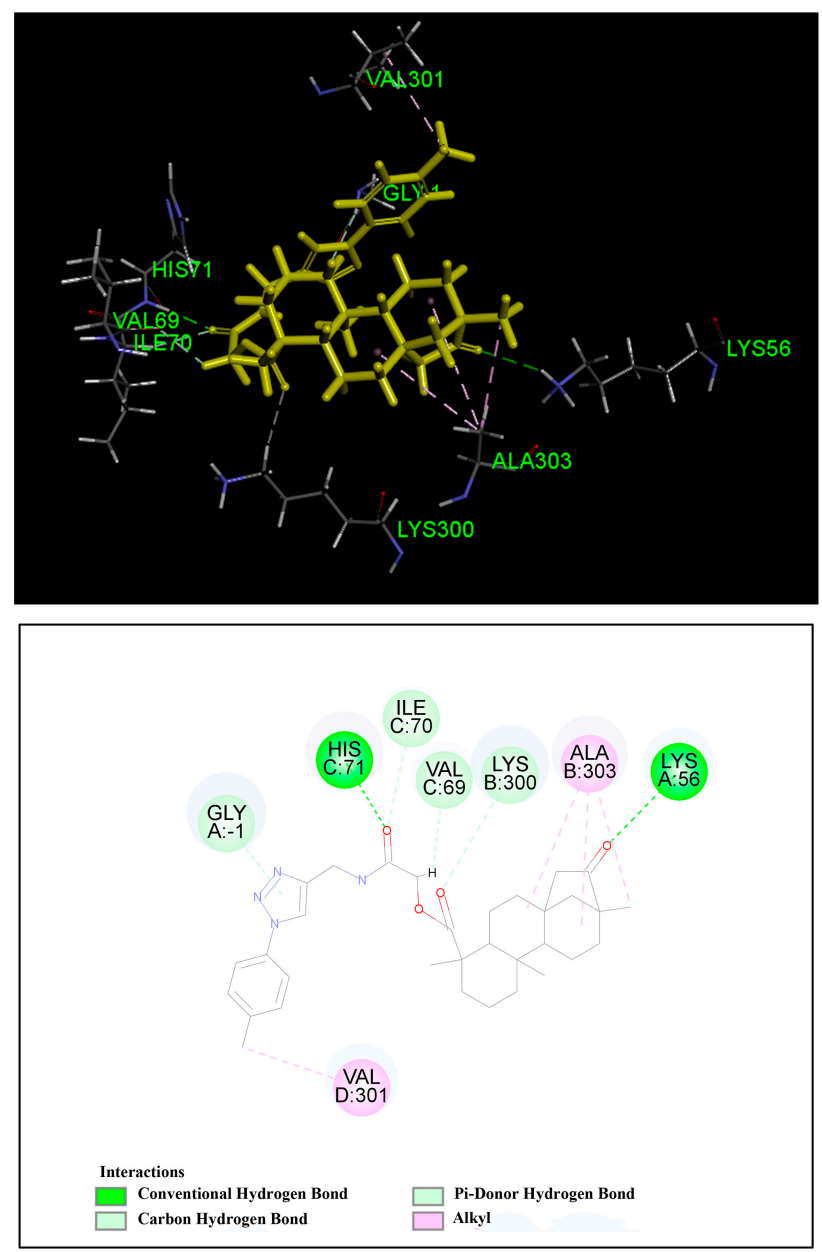

Figure 6. Computer modelling of compound $5 \mathbf{d}$ binding to CDK2/cyclin A (3my5). Compound 5d was colored in yellow.

\section{Materials and Methods}

\subsection{General Procedures}

Melting points were determined in open capillary tubes and were uncorrected. Reactions were monitored by thin-layer chromatography (TLC) on silica gel plates. ${ }^{1} \mathrm{H}-\mathrm{NMR}$ and ${ }^{13} \mathrm{C}-\mathrm{NMR}$ spectra were measured on an AV-300 (Bruker BioSpin, Fällanden, Switzerland) and AV-500 (Bruker BioSpin, Fällanden, Switzerland) and all chemical shifts were given in ppm relative to tetramethylsilane (TMS). High-resolution mass spectra were measured using a matrix-assisted laser desorption/ionization (MALDI)-time of flight (TOF)/TOF mass spectrometer (Bruker Daltonik, Bremen, Germany). The major chemicals were purchased from Aldrich Chemical Corporation (Milwaukee, WI, USA). All other chemicals were of analytical grade.

\subsection{General Procedure for the Synthesis of Compound $(\mathbf{1 a}-\mathbf{1 c})$}

Isosteviol (63.6 mg, $0.20 \mathrm{mmol})$ was placed in $\mathrm{CHCl}_{3}(10 \mathrm{~mL})$, oxalyl chloride $(38.1 \mathrm{mg}, 0.30 \mathrm{mmol})$ was added and the mixture was stirred at $60{ }^{\circ} \mathrm{C}$ for $2 \mathrm{~h}$. Upon completion, the solvent was evaporated in vacuo to obtain the crude product, a colorless crystal, which was used in the next step without further purification. Next, the crude product and different amines $(0.21 \mathrm{mmol})$ and $\mathrm{Et}_{3} \mathrm{~N}(22.2 \mathrm{mg}$, 
$0.22 \mathrm{mmol})$ were added to $\mathrm{CH}_{2} \mathrm{Cl}_{2}(10 \mathrm{~mL})$ and the resulting mixture was stirred at $30{ }^{\circ} \mathrm{C}$ for $2 \mathrm{~h}$. Then, the solvent was evaporated in vacuo, water was added $(10 \mathrm{~mL})$, the mixture was filtered and the residue was washed with water to obtain the target compounds (1a-1c) as white powders.

(4R,4aS,6aR,9S,11aR,11bS)-4,9,11b-trimethyl-8-oxo-N-(2-(pyrrolidin-1-yl)ethyl)tetradecahydro-6a,9methanocyclohepta[a]naphthalene-4-carboxamide (1a). White powder; yield, 71\%; m.p. $136-137{ }^{\circ} \mathrm{C} ;{ }^{1} \mathrm{H}-\mathrm{NMR}$ $\left(\mathrm{CDCl}_{3}, 300 \mathrm{MHz}, \mathrm{ppm}\right): \delta 6.34$ (brs, $\left.1 \mathrm{H},-\mathrm{CO}-\mathrm{NH}-\right), 3.31$ (q, J = $\left.6 \mathrm{~Hz}, 2 \mathrm{H},-\mathrm{CO}-\mathrm{NH}-\mathrm{CH}_{2}-\right), 2.70-2.51$ (m, $\left.7 \mathrm{H}, \mathrm{N}\left(\mathrm{CH}_{2}\right)_{3}, 15-\mathrm{He}\right), 2.10(\mathrm{~d}, J=12 \mathrm{~Hz}, 1 \mathrm{H}, 3-\mathrm{He}), 2.00-1.95(\mathrm{~m}, 1 \mathrm{H}), 1.89-1.86(\mathrm{~m}, 1 \mathrm{H}), 1.83-1.75(\mathrm{~m}$, 8H), 1.71-1.64 (m, 2H), 1.60-1.59 (m, 1H), 1.55 (s, 1H), 1.50-1.49 (m, 1H), 1.45-1.44 (m, 1H), 1.41-1.38 $(\mathrm{m}, 1 \mathrm{H}), 1.35-1.23(\mathrm{~m}, 2 \mathrm{H}), 1.19\left(\mathrm{~s}, 3 \mathrm{H}, 18-\mathrm{CH}_{3}\right), 1.16-1.07(\mathrm{~m}, 2 \mathrm{H}), 0.99\left(\mathrm{~s}, 3 \mathrm{H}, 17-\mathrm{CH}_{3}\right), 0.95-0.89(\mathrm{~m}$, 1H), 0.79 (s, 3H, 20-CH $) .{ }^{13} \mathrm{C}-\mathrm{NMR}\left(\mathrm{CDCl}_{3}, 75 \mathrm{MHz}, \mathrm{ppm}\right): \delta 222.40,176.70,57.49,54.75,54.26,53.78$, 53.61(2C), 48.71, 48.38, 43.61, 41.80, 40.26, 39.50, 38.11(2C), 37.92, 37.31, 30.21, 23.63(2C), 22.01, 20.33, 19.86, 19.04, 13.41. HRMS $(m / z)$ : calcd for $\mathrm{C}_{26} \mathrm{H}_{43} \mathrm{~N}_{2} \mathrm{O}_{2}{ }^{+}[\mathrm{M}+\mathrm{H}]^{+}: 415.3319$, found: 415.3316 .

(4R,4aS,6aR,9S,11aR,11bS)-N-(2-(dimethylamino)ethyl)-4,9,11b-trimethyl-8-oxotetradecahydro-6a,9methanocyclohepta[a]naphthalene-4-carboxamide (1b). White powder; yield, 66\%; m.p. $102-103{ }^{\circ} \mathrm{C}$; ${ }^{1} \mathrm{H}-\mathrm{NMR}\left(\mathrm{CDCl}_{3}, 300 \mathrm{MHz}, \mathrm{ppm}\right): \delta 6.30$ (brs, $\left.1 \mathrm{H},-\mathrm{CO}-\mathrm{NH}-\right), 2.29$ (q, J = $6 \mathrm{~Hz}, 2 \mathrm{H},-\mathrm{CO}-\mathrm{NH}_{-}-\underline{\mathrm{H}}_{2}-$ ), $2.67(\mathrm{dd}, J=18,3 \mathrm{~Hz}, 1 \mathrm{H}, 15-\mathrm{He}), 2.41\left(\mathrm{t}, J=6 \mathrm{~Hz}, 2 \mathrm{H},-\mathrm{CO}-\mathrm{NH}-\mathrm{CH}_{2}-\right), 2.29-2.19\left(\mathrm{~m}, 6 \mathrm{H}, \mathrm{N}\left(\mathrm{CH}_{2}\right)_{3}\right)$, $2.09(\mathrm{~d}, \mathrm{~J}=12 \mathrm{~Hz}, 1 \mathrm{H}, 3-\mathrm{He}), 2.02-1.94(\mathrm{~m}, 1 \mathrm{H}, 6-\mathrm{He}), 1.88-1.78$ (m, 3H), 1.76-1.68 (m, 3H), $1.64-1.59$ $(\mathrm{m}, 2 \mathrm{H}), 1.55-1.48(\mathrm{~m}, 2 \mathrm{H}), 1.45-1.38(\mathrm{~m}, 3 \mathrm{H}), 1.36-1.31(\mathrm{~m}, 1 \mathrm{H}), 1.27\left(\mathrm{~s}, 3 \mathrm{H}, 18-\mathrm{CH}_{3}\right), 1.16-1.09(\mathrm{~m}$, $2 \mathrm{H}), 0.99\left(\mathrm{~s}, 3 \mathrm{H}, 17-\mathrm{CH}_{3}\right), 0.95-0.90(\mathrm{~m}, 1 \mathrm{H}), 0.79\left(\mathrm{~s}, 3 \mathrm{H}, 20-\mathrm{CH}_{3}\right) .{ }^{13} \mathrm{C}-\mathrm{NMR}\left(\mathrm{CDCl}_{3}, 75 \mathrm{MHz}, \mathrm{ppm}\right): \delta$ 222.43, 176.71, 57.55(2C), 54.75, 54.28, 48.71, 48.37, 45.09(2C), 43.62, 41.79, 40.25, 39.51, 38.09(2C), 37.32, $36.73,30.18,22.04,20.34,19.86,19.11,13.44$. HRMS $(m / z)$ : calcd for $\mathrm{C}_{24} \mathrm{H}_{41} \mathrm{~N}_{2} \mathrm{O}_{2}{ }^{+}[\mathrm{M}+\mathrm{H}]^{+}: 389.3163$, found: 389.3166 .

(4R,4aS,6aR,9S,11aR,11bS)-N-methoxy-N,4,9,11b-tetramethyl-8-oxotetradecahydro-6a,9-methanocyclohepta [a]naphthalene-4-carboxamide (1c). White powder; yield, 68\%; m.p. $144-145{ }^{\circ} \mathrm{C} ;{ }^{1} \mathrm{H}-\mathrm{NMR}\left(\mathrm{CDCl}_{3}\right.$, $300 \mathrm{MHz}, \mathrm{ppm}): \delta 3.66$ (s, 3H, -O-CH 3$), 3.12\left(\mathrm{~s}, 3 \mathrm{H},-\mathrm{N}-\mathrm{CH}_{3}\right), 2.73$ (dd, J = 18, $\left.3 \mathrm{~Hz}, 1 \mathrm{H}, 15-\mathrm{He}\right), 2.53$ (d, $J=12 \mathrm{~Hz}, 1 \mathrm{H}, 3-\mathrm{He}), 2.16-2.02(\mathrm{~m}, 1 \mathrm{H}, 6-\mathrm{He}), 1.90-1.78(\mathrm{~m}, 2 \mathrm{H}), 1.74-1.58(\mathrm{~m}, 6 \mathrm{H}), 1.54-1.34(\mathrm{~m}, 5 \mathrm{H})$, $1.28\left(\mathrm{~s}, 3 \mathrm{H}, 18-\mathrm{CH}_{3}\right), 1.22-1.17(\mathrm{~m}, 1 \mathrm{H}), 1.13-1.04(\mathrm{~m}, 2 \mathrm{H}), 0.99\left(\mathrm{~s}, 3 \mathrm{H}, 17-\mathrm{CH}_{3}\right), 0.96-0.90(\mathrm{~m}, 1 \mathrm{H}), 0.83$ (s, 3H, 20-CH $) .{ }^{13} \mathrm{C}-\mathrm{NMR}\left(\mathrm{CDCl}_{3}, 75 \mathrm{MHz}, \mathrm{ppm}\right): \delta 222.81,178.30,60.94,60.46,55.71,54.43,48.72$, $48.51,46.21,42.36,40.91,39.66,38.55,38.44,37.40,34.38,27.22,22.31,20.43,20.13,19.90,15.48$. HRMS $(m / z)$ : calcd for $\mathrm{C}_{22} \mathrm{H}_{36} \mathrm{NO}_{3}{ }^{+}[\mathrm{M}+\mathrm{H}]^{+}: 362.2690$, found: 362.2987.

\subsection{General Procedure for the Synthesis of Compound $(2 a-2 e)$}

A mixture of isosteviol $(63.6 \mathrm{mg}, 0.20 \mathrm{mmol}), \mathrm{K}_{2} \mathrm{CO}_{3}(41.5 \mathrm{mg}, 0.30 \mathrm{mmol})$ and chlorinated derivatives $(0.21 \mathrm{mmol})$ in $\mathrm{CH}_{3} \mathrm{CN}(10 \mathrm{~mL})$ was stirred at $80^{\circ} \mathrm{C}$ for $4 \mathrm{~h}$. After confirming the reaction progress by thin-layer chromatography, the solvent was evaporated in vacuo, the mixture was dissolved with $15 \mathrm{~mL}$ ethyl acetate and then washed with saline $(5 \mathrm{~mL} \times 3)$. The mixture was then purified using silica gel column chromatography and eluted with petroleum ether:ethyl acetate (5:1) to obtain the target compound $\mathbf{2 a}-\mathbf{2 e}$.

2-(4-methylpiperazin-1-yl)-2-oxoethyl(4R,4aS,6aR,9S,11aR,11bS)-4,9,11b-trimethyl-8-oxotetradecahydro-6a, 9-methanocyclohepta[a]naphthalene-4-carboxylate (2a). White powder; yield, 87\%; m.p. $112-113{ }^{\circ} \mathrm{C}$; ${ }^{1} \mathrm{H}-\mathrm{NMR}\left(\mathrm{CDCl}_{3}, 300 \mathrm{MHz}, \mathrm{ppm}\right): \delta 4.82$ (d, $\left.J=15 \mathrm{~Hz}, 1 \mathrm{H},-\mathrm{O}-\mathrm{CHe}-\mathrm{CO}-\right), 4.63(\mathrm{~d}, J=15 \mathrm{~Hz}, 1 \mathrm{H}$, -O-CHa-CO-), 3.65 (s, 2H, -CO-N-CH $2^{-}$), 3.45 (s, 2H, -CO-N-CH $2^{-}$), 2.65 (dd, J = 12, 3 Hz, 1H, 15-He), 2.45-2.26 (m, 8H, 3-He, - $\left.\left(\mathrm{CH}_{2}\right)_{2}-\mathrm{N}-\mathrm{CH}_{3}\right), 1.97-1.84(\mathrm{~m}, 3 \mathrm{H}), 1.78-1.65(\mathrm{~m}, 4 \mathrm{H}), 1.60-1.55(\mathrm{~m}, 2 \mathrm{H})$, $1.50-1.40(\mathrm{~m}, 4 \mathrm{H}), 1.32\left(\mathrm{~s}, 3 \mathrm{H}, 18-\mathrm{CH}_{3}\right), 1.28-1.21(\mathrm{~m}, 3 \mathrm{H}), 1.16-1.07(\mathrm{~m}, 1 \mathrm{H}), 0.99\left(\mathrm{~s}, 3 \mathrm{H}, 17-\mathrm{CH}_{3}\right)$, 0.95-0.88 (m, 1H), 0.75 (s, 3H, 20-CH $) .{ }^{13} \mathrm{C}-\mathrm{NMR}\left(\mathrm{CDCl}_{3}, 125 \mathrm{MHz}, \mathrm{ppm}\right): \delta 222.50,176.89,165.02$, 60.69, 57.16, 54.77, 54.70, 54.38, 54.33, 50.90, 48.73, 48.51, 45.85, 44.24, 44.08, 41.54, 39.82, 39.48, 38.11, $37.98,37.33,29.06,21.65,20.34,19.87,18.99,13.57$. HRMS $(m / z)$ : calcd for $\mathrm{C}_{27} \mathrm{H}_{43} \mathrm{~N}_{2} \mathrm{O}_{4}{ }^{+}[\mathrm{M}+\mathrm{H}]^{+}$: 459.3217, found: 459.3221 . 
2-(4-ethylpiperazin-1-yl)-2-oxoethyl(4R,4aS,6aR,9S,11aR,11bS)-4,9,11b-trimethyl-8-oxotetradecahydro-6a, 9-methanocyclohepta[a]naphthalene-4-carboxylate (2b). White crystal; yield, 84\%; m.p. $115-117{ }^{\circ} \mathrm{C}$; ${ }^{1} \mathrm{H}-\mathrm{NMR}\left(\mathrm{CDCl}_{3}, 500 \mathrm{MHz}, \mathrm{ppm}\right): \delta 4.81$ (d, $\left.J=9 \mathrm{~Hz}, 1 \mathrm{H},-\mathrm{O}-\mathrm{CHe}-\mathrm{CO}-\right), 4.62(\mathrm{~d}, J=9 \mathrm{~Hz}, 1 \mathrm{H}$, -O-CHa-CO-), 3.64 (s, 2H, -CO-N-CH2-), 3.42 (s, 2H, -CO-N-CH $2^{-}$), 2.63 (d, J = 12 Hz, 1H, 15-He), 2.45-2.43 (m, 6H, - $\left.\left(\mathrm{CH}_{2}\right)_{2}-\mathrm{N}-\mathrm{CH}_{2}-\right), 2.27$ (d, J = 9 Hz, 1H, 3-He), 1.95-1.92 (m, 1H), 1.87-1.78 (m, 3H), 1.73-1.65 (m, 3H), $1.61(\mathrm{~d}, J=9 \mathrm{~Hz}, 1 \mathrm{H}), 1.55(\mathrm{~d}, J=6 \mathrm{~Hz}, 1 \mathrm{H}), 1.51-1.34(\mathrm{~m}, 4 \mathrm{H}), 1.31\left(\mathrm{~s}, 3 \mathrm{H}, 18-\mathrm{CH}_{3}\right)$, 1.26-1.15 (m, 4H), 1.11-1.06 (m, 3H, $\left.-\mathrm{NCH}_{2} \mathrm{CH}_{3}\right), 0.97\left(\mathrm{~s}, 3 \mathrm{H}, 17-\mathrm{CH}_{3}\right), 0.94-0.89(\mathrm{~m}, 1 \mathrm{H}), 0.74(\mathrm{~s}, 3 \mathrm{H}$, $\left.20-\mathrm{CH}_{3}\right) .{ }^{13} \mathrm{C}-\mathrm{NMR}\left(\mathrm{CDCl}_{3}, 75 \mathrm{MHz}, \mathrm{ppm}\right): \delta 222.57,176.85,164.93,60.72,57.13,54.74,54.30,52.62$, 52.20, 52.13, 48.70, 48.48, 44.40, 44.05, 41.72, 41.51, 39.80, 39.46, 38.08, 37.96, 37.31, 29.04, 21.63, 20.32, $19.85,18.97,13.55,11.77$. HRMS $(m / z)$ : calcd for $\mathrm{C}_{28} \mathrm{H}_{45} \mathrm{~N}_{2} \mathrm{O}_{4}{ }^{+}[\mathrm{M}+\mathrm{H}]^{+}:$: 473.3374, found: 473.3379 .

2-oxo-2-(4-phenylpiperazin-1-yl)ethyl(4R,4aS,6aR,9S,11aR,11bS)-4,9,11b-trimethyl-8-oxotetradecahydro-6a, 9-methanocyclohepta[a]naphthalene-4-carboxylate (2c). White crystal; yield, 81\%; m.p. $143-144{ }^{\circ} \mathrm{C}$; ${ }^{1} \mathrm{H}-\mathrm{NMR}\left(\mathrm{CDCl}_{3}, 300 \mathrm{MHz}, \mathrm{ppm}\right): \delta$ 7.34-7.30 (m, 2H, Ar-H), 6.96-6.92 (m, 3H, Ar-H), 4.88 (d, $J=15 \mathrm{~Hz}, 1 \mathrm{H},-\mathrm{O}-\mathrm{CHe}-\mathrm{CO}-), 4.70$ (d, J = $15 \mathrm{~Hz}, 1 \mathrm{H},-\mathrm{O}-\mathrm{CHa}-\mathrm{CO}-), 3.80$ (s, 2H, -CO-N-CH $\left.2^{-}\right), 3.59$ (s,

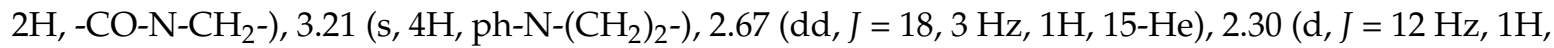
3-He), 1.99-1.94 (m, 1H), 1.90-1.77 (m, 3H), 1.74-1.66 (m, 3H), 1.56-1.50 (m, 2H), 1.46-1.39 (m, 2H), $1.34\left(\mathrm{~s}, 3 \mathrm{H}, 18-\mathrm{CH}_{3}\right), 1.27(\mathrm{~s}, 2 \mathrm{H}), 1.23-1.04(\mathrm{~m}, 4 \mathrm{H}), 1.00\left(\mathrm{~s}, 3 \mathrm{H}, 17-\mathrm{CH}_{3}\right), 0.95-0.89(\mathrm{~m}, 1 \mathrm{H}), 0.77(\mathrm{~s}$, $\left.3 \mathrm{H}, 20-\mathrm{CH}_{3}\right) .{ }^{13} \mathrm{C}-\mathrm{NMR}\left(\mathrm{CDCl}_{3}, 75 \mathrm{MHz}, \mathrm{ppm}\right): \delta 222.44,176.85,165.09,150.82,129.28(2 \mathrm{C}), 120.77$, 116.80(2C), 60.73, 57.16, 54.77, 54.32, 49.66, 49.39, 48.71, 48.50, 44.56, 44.08, 41.80, 41.53, 39.81, 39.47, $38.11,37.99,37.32,29.07,21.65,20.34,19.87,18.99,13.58$. HRMS $(m / z)$ : calcd for $\mathrm{C}_{32} \mathrm{H}_{45} \mathrm{~N}_{2} \mathrm{O}_{4}{ }^{+}[\mathrm{M}+$ $\mathrm{H}]^{+}:$521.3374, found: 521.3370 .

2-(4-benzylpiperazin-1-yl)-2-oxoethyl(4R,4aS,6aR,9S,11aR,11bS)-4,9,11b-trimethyl-8-oxotetradecahydro-6a, 9-methanocyclohepta[a]naphthalene-4-carboxylate (2d). White powder; yield, 83\%; m.p. $149-150{ }^{\circ} \mathrm{C}$; ${ }^{1} \mathrm{H}-\mathrm{NMR}\left(\mathrm{CDCl}_{3}, 300 \mathrm{MHz}, \mathrm{ppm}\right): \delta 7.38-7.31$ (m, 5H, Ar-H), 4.82 (d, J = $\left.15 \mathrm{~Hz}, 1 \mathrm{H},-\mathrm{O}-\mathrm{CHe}-\mathrm{CO}-\right)$, 4.63 (d, J = $15 \mathrm{~Hz}, 1 \mathrm{H},-\mathrm{O}-\mathrm{CHa}-\mathrm{CO}-), 3.64$ (s, 2H, -CO-N-CH $\left.2^{-}\right), 3.54$ (s, 2H, -N-CH2-ph), 3.41 (s, $2 \mathrm{H}$, -CO-N-CH $\left.2^{-}\right), 2.66(\mathrm{dd}, J=18,3 \mathrm{~Hz}, 1 \mathrm{H}, 15-\mathrm{He}), 2.46\left(\mathrm{~s}, 4 \mathrm{H},-\mathrm{N}-\left(\mathrm{CH}_{2}\right)_{2}-\right), 2.29$ (d, J=12 Hz, 1H, 3-He), 1.97-1.92 (m, 1H), $1.85(\mathrm{~s}, 1 \mathrm{H}), 1.78-1.70(\mathrm{~m}, 4 \mathrm{H}), 1.66-1.59(\mathrm{~m}, 3 \mathrm{H}), 1.55(\mathrm{~s}, 1 \mathrm{H}), 1.50-1.40(\mathrm{~m}, 3 \mathrm{H}), 1.27$ $\left(\mathrm{s}, 3 \mathrm{H}, 18-\mathrm{CH}_{3}\right), 1.22-1.16(\mathrm{~m}, 3 \mathrm{H}), 1.13-1.07(\mathrm{~m}, 1 \mathrm{H}), 0.99\left(\mathrm{~s}, 3 \mathrm{H}, 17-\mathrm{CH}_{3}\right), 0.94-0.85(\mathrm{~m}, 1 \mathrm{H}), 0.76(\mathrm{~s}$, $\left.3 \mathrm{H}, 20-\mathrm{CH}_{3}\right) .{ }^{13} \mathrm{C}-\mathrm{NMR}\left(\mathrm{CDCl}_{3}, 75 \mathrm{MHz}, \mathrm{ppm}\right): \delta 222.57,176.85,164.94,137.47,129.10(2 \mathrm{C}), 128.37(2 \mathrm{C})$, 127.35, 62.84, 60.74, 57.15, 54.76, 54.32, 52.84, 52.53, 48.72, 48.49, 44.53, 44.06, 41.90, 41.53, 39.81, 39.47, $38.09,37.97,37.32,29.06,21.63,20.33,19.86,18.99,13.56$. HRMS $(m / z)$ : calcd for $\mathrm{C}_{33} \mathrm{H}_{47} \mathrm{~N}_{2} \mathrm{O}_{4}{ }^{+}\left[\mathrm{M}_{+}\right.$ $\mathrm{H}]^{+}:$535.3530, found: 535.3525 .

2-(azepan-1-yl)-2-oxoethyl(4R,4aS,6aR,9S,11aR,11bS)-4,9,11b-trimethyl-8-oxotetradecahydro-6a,9methanocyclohepta[a]naphthalene-4-carboxylate (2e). White powder; yield, 83\%; m.p. $110-112{ }^{\circ} \mathrm{C}$; ${ }^{1} \mathrm{H}-\mathrm{NMR}\left(\mathrm{CDCl}_{3}, 300 \mathrm{MHz}, \mathrm{ppm}\right): \delta 4.84$ (d, J = $\left.15 \mathrm{~Hz}, 1 \mathrm{H},-\mathrm{O}-\mathrm{CHe}-\mathrm{CO}-\right), 4.62$ (d, J = $15 \mathrm{~Hz}, 1 \mathrm{H}$, -O-CHa-CO-), 3.55 (t, J = $\left.6 \mathrm{~Hz}, 2 \mathrm{H},-\mathrm{CO}-\mathrm{N}-\mathrm{CH}_{2}-\right), 3.39$ (t, J = $\left.6 \mathrm{~Hz}, 2 \mathrm{H},-\mathrm{CO}-\mathrm{N}-\mathrm{CH}_{2}-\right), 2.67$ (dd, J = 18, $3 \mathrm{~Hz}, 1 \mathrm{H}, 15-\mathrm{He}), 2.31$ (d, J = $12 \mathrm{~Hz}, 1 \mathrm{H}, 3-\mathrm{He}), 1.99-1.82(\mathrm{~m}, 3 \mathrm{H}), 1.79-1.71(\mathrm{~m}, 7 \mathrm{H}), 1.66-1.59(\mathrm{~m}, 7 \mathrm{H})$, $1.55(\mathrm{~s}, 1 \mathrm{H}), 1.50-1.38(\mathrm{~m}, 4 \mathrm{H}), 1.34\left(\mathrm{~s}, 3 \mathrm{H}, 18-\mathrm{CH}_{3}\right), 1.12-1.07(\mathrm{~m}, 1 \mathrm{H}),, 0.99\left(\mathrm{~s}, 3 \mathrm{H}, 17-\mathrm{CH}_{3}\right), 0.94-0.84$ $(\mathrm{m}, 3 \mathrm{H}), 0.76\left(\mathrm{~s}, 3 \mathrm{H}, 20-\mathrm{CH}_{3}\right) .{ }^{13} \mathrm{C}-\mathrm{NMR}\left(\mathrm{CDCl}_{3}, 75 \mathrm{MHz}, \mathrm{ppm}\right): \delta 222.60,176.92,166.05,60.69,57.18$, 54.76, 54.32, 48.71, 48.50, 46.46, 45.99, 44.02, 41.55, 39.85, 39.47, 38.10, 37.98, 37.33, 29.08, 28.93, 27.47, $27.22,26.89,21.64,20.32,19.87,19.01,13.56$. HRMS $(m / z)$ : calcd for $\mathrm{C}_{28} \mathrm{H}_{44} \mathrm{NO}_{4}{ }^{+}[\mathrm{M}+\mathrm{H}]^{+}: 458.3265$, found: 458.3261 .

\subsection{General Procedure for the Synthesis of Compound (3a-3d)}

A mixture of isosteviol (63.6 mg, $0.20 \mathrm{mmol}), \mathrm{EDC} \cdot \mathrm{HCl}(42.2 \mathrm{mg}, 0.22 \mathrm{mmol}), \mathrm{HOBt}(29.7 \mathrm{mg}$, $0.22 \mathrm{mmol}), \mathrm{Et}_{3} \mathrm{~N}(102 \mu \mathrm{L}, 0.30 \mathrm{mmol})$ and various amino acid esters $(0.30 \mathrm{mmol})$ in $\mathrm{CHCl}_{3}(10 \mathrm{~mL})$ was stirred at $60^{\circ} \mathrm{C}$ for $8 \mathrm{~h}$. After confirming the reaction progress by thin-layer chromatography, the solvent was evaporated in vacuo, the mixture was dissolved with $15 \mathrm{~mL}$ ethyl acetate and then washed 
with saline $(5 \mathrm{~mL} \times 3)$. The mixture was then purified using silica gel column chromatography and eluted with a gradient of petroleum ether:ethyl acetate (10:1-5:1) to obtain the target compound 3a-3d.

Methyl(S)-2-phenyl-2-((4R,4aS,6aR,9S,11aR,11bS)-4,9,11b-trimethyl-8-oxotetradecahydro-6a,9methanocyclohepta[a]naphthalene-4-carboxamido)acetate (3a). White crystal; yield, 70\%; m.p. $143-145^{\circ} \mathrm{C}$; ${ }^{1} \mathrm{H}-\mathrm{NMR}\left(\mathrm{CDCl}_{3}, 300 \mathrm{MHz}, \mathrm{ppm}\right): 87.40-7.33(\mathrm{~m}, 5 \mathrm{H}, \mathrm{Ar}-\mathrm{H}), 6.67$ (d, J = 9 Hz, 1H, -CO-NH-), 5.56 (d, $J=9 \mathrm{~Hz}, 1 \mathrm{H},-\mathrm{NH}-\mathrm{C} \underline{\mathrm{H}}-\mathrm{ph}), 3.75\left(\mathrm{~s}, 3 \mathrm{H},-\mathrm{OCH}_{3}\right), 2.59(\mathrm{dd}, J=18,3 \mathrm{~Hz}, 1 \mathrm{H}, 15-\mathrm{He}), 2.13(\mathrm{~d}, J=15 \mathrm{~Hz}, 1 \mathrm{H}$, 3-He), 1.99-1.85 (m, 2H), 1.81-1.66 (m, 5H), $1.61(\mathrm{~s}, 4 \mathrm{H}), 1.54-1.51(\mathrm{~m}, 1 \mathrm{H}), 1.48-1.39(\mathrm{~m}, 2 \mathrm{H}), 1.24-1.20$ $(\mathrm{m}, 5 \mathrm{H}), 1.15-1.13(\mathrm{~m}, 1 \mathrm{H}), 0.99\left(\mathrm{~s}, 3 \mathrm{H}, 17-\mathrm{CH}_{3}\right), 0.94-0.87(\mathrm{~m}, 1 \mathrm{H}), 0.65\left(\mathrm{~s}, 3 \mathrm{H}, 20-\mathrm{CH}_{3}\right) .{ }^{13} \mathrm{C}-\mathrm{NMR}$ $\left(\mathrm{CDCl}_{3}, 75 \mathrm{MHz}, \mathrm{ppm}\right): \delta 222.40,175.88,171.76,136.77,128.94(2 \mathrm{C}), 128.47,127.30(2 \mathrm{C}), 57.49,56.36$, 54.73, 54.25, 52.77, 48.70, 48.32, 43.70, 41.67, 40.14, 39.47, 38.10, 38.08, 37.28, 29.93, 22.11, 20.30, 19.85, 19.04, 13.40. HRMS $(m / z)$ : calcd for $\mathrm{C}_{29} \mathrm{H}_{40} \mathrm{NO}_{4}{ }^{+}[\mathrm{M}+\mathrm{H}]^{+}: 466.2952$, found: 466.2947 .

Methyl((4R,4aS,6aR,9S,11aR,11bS)-4,9,11b-trimethyl-8-oxotetradecahydro-6a,9-methanocyclohepta[a] naphthalene-4-carbonyl)-D-phenylalaninate (3b). White crystal; yield, 76\%; m.p. $147-148{ }^{\circ} \mathrm{C} ;{ }^{1} \mathrm{H}-\mathrm{NMR}$ $\left(\mathrm{CDCl}_{3}, 300 \mathrm{MHz}, \mathrm{ppm}\right): \delta$ 7.33-7.25 (m, 3H, Ar-H), 7.15-7.13 (m, 2H, Ar-H), $5.97(\mathrm{~d}, J=6 \mathrm{~Hz}, 1 \mathrm{H}$, -CO-NH-), 4.84 (dd, $J=15,9 \mathrm{~Hz}, 1 \mathrm{H},-\mathrm{NH}-\mathrm{C} \underline{\mathrm{H}}-\mathrm{ph}), 3.75\left(\mathrm{~s}, 3 \mathrm{H},-\mathrm{OCH}_{3}\right), 3.19$ (dd, $J=15,6 \mathrm{~Hz}, 1 \mathrm{H}$, ph-C $\underline{\mathrm{He}}-), 3.06$ (dd, $J=15,6 \mathrm{~Hz}, 1 \mathrm{H}$, ph-C $\underline{\mathrm{Ha}}-), 2.63$ (dd, $J=18,3 \mathrm{~Hz}, 1 \mathrm{H}, 15-\mathrm{He}), 2.05$ (d, $J=15 \mathrm{~Hz}, 1 \mathrm{H}$, 3-He), 1.82 (s, 2H), 1.76-1.73 (m, 2H), 1.68-1.64 (m, 5H), 1.59-1.56 (m, 2H), 1.53-1.48 (m, 1H), 1.45-1.33 $(\mathrm{m}, 4 \mathrm{H}), 1.27\left(\mathrm{~s}, 3 \mathrm{H}, 18-\mathrm{CH}_{3}\right), 0.98\left(\mathrm{~s}, 3 \mathrm{H}, 17-\mathrm{CH}_{3}\right), 0.92-0.81(\mathrm{~m}, 2 \mathrm{H}), 0.61\left(\mathrm{~s}, 3 \mathrm{H}, 20-\mathrm{CH}_{3}\right) .{ }^{13} \mathrm{C}-\mathrm{NMR}$ $\left(\mathrm{CDCl}_{3}, 75 \mathrm{MHz}, \mathrm{ppm}\right): \delta 222.44,176.48,172.43,136.09,129.14(2 \mathrm{C}), 128.65(2 \mathrm{C}), 127.17,57.33,54.71$, 54.20, 53.00, 52.29, 48.70, 48.34, 43.74, 41.66, 40.16, 39.49, 38.17, 38.08, 37.82, 37.29, 29.84, 21.88, 20.32, 19.84, 18.89, 13.38. HRMS ( $m / z)$ : calcd for $\mathrm{C}_{30} \mathrm{H}_{42} \mathrm{NO}_{4}{ }^{+}[\mathrm{M}+\mathrm{H}]^{+}: 480.3108$, found: 480.3100 .

Methyl((4R,4aS,6aR,9S,11aR,11bS)-4,9,11b-trimethyl-8-oxotetradecahydro-6a,9-methanocyclohepta[a] naphthalene-4-carbonyl)-L-valinate (3c). White powder; yield, 71\%; m.p. $96-98{ }^{\circ} \mathrm{C} ;{ }^{1} \mathrm{H}-\mathrm{NMR}\left(\mathrm{CDCl}_{3}\right.$,

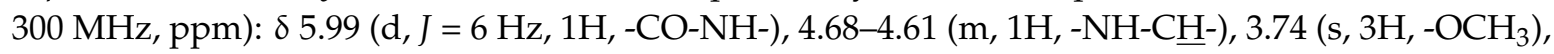
$2.66(\mathrm{dd}, J=18,3 \mathrm{~Hz}, 1 \mathrm{H}, 15-\mathrm{He}), 2.10-1.96(\mathrm{~m}, 2 \mathrm{H}), 1.89-1.84(\mathrm{~m}, 2 \mathrm{H}), 1.80-1.75(\mathrm{~m}, 2 \mathrm{H}), 1.72-1.58(\mathrm{~m}$, 7H), 1.55-1.48 (m, 3H), 1.45-1.38 (m, 2H), $1.27(\mathrm{~s}, 2 \mathrm{H}), 1.25-1.20(\mathrm{~m}, 5 \mathrm{H}), 1.18-1.14(\mathrm{~m}, 1 \mathrm{H}), 0.99(\mathrm{~s}, 3 \mathrm{H}$, 17- $\left.\mathrm{CH}_{3}\right), 0.97-0.92(\mathrm{~m}, 5 \mathrm{H}), 0.77\left(\mathrm{~s}, 3 \mathrm{H}, 20-\mathrm{CH}_{3}\right) .{ }^{13} \mathrm{C}-\mathrm{NMR}\left(\mathrm{CDCl}_{3}, 75 \mathrm{MHz}, \mathrm{ppm}\right): \delta 222.39,176.41$, $173.84,57.54,54.68,54.25,52.16,50.36,48.69,48.34,43.76,41.70,41.61,40.17,39.48,38.08(2 \mathrm{C}), 37.28$, $30.11,25.06,22.85,22.17,21.91,20.31,19.84,19.00,13.53$. HRMS $(m / z)$ : calcd for $\mathrm{C}_{27} \mathrm{H}_{44} \mathrm{NO}_{4}{ }^{+}[\mathrm{M}+$ $\mathrm{H}]^{+}$: 446.3265, found: 446.3260 .

Methyl((4R,4aS,6aR,9S,11aR,11bS)-4,9,11b-trimethyl-8-oxotetradecahydro-6a,9-methanocyclohepta[a] naphthalene-4-carbonyl)-L-tryptophanate (3d). White crystal; yield, 74\%; m.p. $165-166{ }^{\circ} \mathrm{C} ;{ }^{1} \mathrm{H}-\mathrm{NMR}$ $\left(\mathrm{CDCl}_{3}, 300 \mathrm{MHz}, \mathrm{ppm}\right): \delta 8.36$ (s, 1H, -NH-), 7.59 (d, J = 6 Hz, 1H, Ar-H), $7.40(\mathrm{~d}, J=9 \mathrm{~Hz}, 1 \mathrm{H}, \mathrm{Ar}-\mathrm{H})$, 7.26-7.12 (m, 2H, Ar-H), 7.05 (s, 1H, -NH-C $\underline{H}=), 6.03$ (d, J = 6 Hz, 1H, -CO-NH-), 4.85 (q, J = 6 Hz, 1H, -NH-C $\underline{-}-), 3.75\left(\mathrm{~s}, 3 \mathrm{H},-\mathrm{OCH}_{3}\right), 3.38-3.20\left(\mathrm{~m}, 2 \mathrm{H}, \mathrm{Ar}-\mathrm{CH}_{2}-\right), 2.40$ (dd, $\left.J=18,3 \mathrm{~Hz}, 1 \mathrm{H}, 15-\mathrm{He}\right), 1.93$ $(\mathrm{d}, J=15 \mathrm{~Hz}, 1 \mathrm{H}, 3-\mathrm{He}), 1.75-1.67(\mathrm{~m}, 5 \mathrm{H}), 1.63-1.56(\mathrm{~m}, 3 \mathrm{H}), 1.51-1.43(\mathrm{~m}, 2 \mathrm{H}), 1.37-1.31(\mathrm{~m}, 5 \mathrm{H})$, $1.28\left(\mathrm{~s}, 3 \mathrm{H}, 18-\mathrm{CH}_{3}\right), 1.10-1.08(\mathrm{~m}, 1 \mathrm{H}), 0.97\left(\mathrm{~s}, 3 \mathrm{H}, 17-\mathrm{CH}_{3}\right), 0.92-0.77(\mathrm{~m}, 2 \mathrm{H}), 0.52\left(\mathrm{~s}, 3 \mathrm{H}, 20-\mathrm{CH}_{3}\right)$. ${ }^{13} \mathrm{C}-\mathrm{NMR}\left(\mathrm{CDCl}_{3}, 75 \mathrm{MHz}, \mathrm{ppm}\right): \delta 222.60,176.60,172.94,136.12,127.60,122.48(2 \mathrm{C}), 119.84,118.50$, $111.43,110.41,57.35,54.62,54.18,53.15,52.29,48.69,48.26,43.53,41.61,40.07,39.32,37.96,37.92,37.24$, 29.85, 27.23, 21.80, 20.24, 19.83, 18.84, 13.08. HRMS $(m / z)$ : calcd for $\mathrm{C}_{32} \mathrm{H}_{43} \mathrm{~N}_{2} \mathrm{O}_{4}{ }^{+}[\mathrm{M}+\mathrm{H}]^{+}: 519.3217$, found: 519.3221 .

\subsection{General Procedure for the Synthesis of Compound $(\mathbf{4 a}-\mathbf{4 j})$}

A mixture of isosteviol $(63.6 \mathrm{mg}, 0.20 \mathrm{mmol}), \mathrm{K}_{2} \mathrm{CO}_{3}(41.5 \mathrm{mg}, 0.30 \mathrm{mmol})$ and different chloroacetanilides $(0.21 \mathrm{mmol})$ in $\mathrm{CH}_{3} \mathrm{CN}(10 \mathrm{~mL})$ was stirred at $80{ }^{\circ} \mathrm{C}$ for $2 \mathrm{~h}$. After confirming the reaction progress by thin-layer chromatography, the solvent was evaporated in vacuo, the mixture was dissolved with $15 \mathrm{~mL}$ ethyl acetate and then washed with saline $(5 \mathrm{~mL} \times 3)$. The mixture was then 
purified using silica gel column chromatography and eluted with a gradient of petroleum ether:ethyl acetate (4:1-5:1) to obtain the target compound $\mathbf{4 a} \mathbf{a}-\mathbf{4} \mathbf{j}$.

2-oxo-2-(phenylamino)ethyl(4R,4aS,6aR,9S,11aR,11bS)-4,9,11b-trimethyl-8-oxotetradecahydro-6a,9methanocyclohepta[a]naphthalene-4-carboxylate (4a). White powder; yield, 86\%; m.p. $154-156{ }^{\circ} \mathrm{C}$; ${ }^{1} \mathrm{H}-\mathrm{NMR}\left(\mathrm{CDCl}_{3}, 300 \mathrm{MHz}, \mathrm{ppm}\right): \delta 7.92(\mathrm{~s}, 1 \mathrm{H},-\mathrm{CO}-\mathrm{NH}-), 7.51(\mathrm{~d}, J=6 \mathrm{~Hz}, 2 \mathrm{H}, \mathrm{Ar}-\mathrm{H}), 7.35(\mathrm{t}$, $J=6 \mathrm{~Hz}, 2 \mathrm{H}, \mathrm{Ar}-\mathrm{H}), 7.15$ (t, $J=6 \mathrm{~Hz}, 1 \mathrm{H}, \mathrm{Ar}-\mathrm{H}), 4.75$ (d, $J=15 \mathrm{~Hz}, 1 \mathrm{H},-\mathrm{O}-\mathrm{CHe}-\mathrm{CO}-), 4.58$ (d, J = $15 \mathrm{~Hz}$, 1H, -O-CHa-CO-), 2.62 (dd, J = 18, $3 \mathrm{~Hz}, 1 \mathrm{H}, 15-\mathrm{He}$ ), 2.28 (d, $J=12 \mathrm{~Hz}, 1 \mathrm{H}, 3-\mathrm{He}), 2.02$ (d, J = $15 \mathrm{~Hz}$, $1 \mathrm{H}, 6-\mathrm{He}), 1.84(\mathrm{~s}, 1 \mathrm{H}), 1.79-1.70(\mathrm{~m}, 5 \mathrm{H}), 1.64-1.54(\mathrm{~m}, 4 \mathrm{H}), 1.51-1.40(\mathrm{~m}, 3 \mathrm{H}), 1.34\left(\mathrm{~s}, 3 \mathrm{H}, 18-\mathrm{CH}_{3}\right)$, $1.23-1.20(\mathrm{~m}, 3 \mathrm{H}), 1.17-1.11(\mathrm{~m}, 1 \mathrm{H}), 0.99\left(\mathrm{~s}, 3 \mathrm{H}, 17-\mathrm{CH}_{3}\right), 0.74\left(\mathrm{~s}, 3 \mathrm{H}, 20-\mathrm{CH}_{3}\right) .{ }^{13} \mathrm{C}-\mathrm{NMR}\left(\mathrm{CDCl}_{3}, 75\right.$ MHz, ppm): $\delta$ 221.95, 175.76, 165.03, 136.83, 129.22(2C), 124.94, 119.74(2C), 63.36, 57.00, 54.71, 54.19, $48.68,48.39,44.03,41.39,39.61,39.43,38.06,37.99,37.20,28.99,22.01,20.34,19.83,18.93,13.50$. HRMS $(m / z)$ : calcd for $\mathrm{C}_{28} \mathrm{H}_{38} \mathrm{NO}_{4}{ }^{+}[\mathrm{M}+\mathrm{H}]^{+}: 452.2795$, found: 452.2790 .

2-((2-chlorophenyl)amino)-2-oxoethyl(4R,4aS,6aR,9S,11aR,11bS)-4,9,11b-trimethyl-8-oxotetradecahydro6a,9-methanocyclohepta[a]naphthalene-4-carboxylate (4b). White powder; yield, 83\%; m.p. $107-108{ }^{\circ} \mathrm{C}$; ${ }^{1} \mathrm{H}-\mathrm{NMR}\left(\mathrm{CDCl}_{3}, 500 \mathrm{MHz}, \mathrm{ppm}\right): \delta 8.46-8.43(\mathrm{~m}, 1 \mathrm{H},-\mathrm{CO}-\mathrm{NH}-), 7.39(\mathrm{~d}, J=10 \mathrm{~Hz}, 1 \mathrm{H}, \mathrm{Ar}-\mathrm{H})$, 7.33-7.29 (m, 2H, Ar-H), 7.09 (t, J = 10 Hz, 1H, Ar-H), 4.79 (d, J = 15 Hz, 1H, -O-CHe-CO-), 4.62 (d, $J=15 \mathrm{~Hz}, 1 \mathrm{H},-\mathrm{O}-\mathrm{CHa}-\mathrm{CO}-), 2.61$ (dd, $J=20,5 \mathrm{~Hz}, 1 \mathrm{H}, 15-\mathrm{He}), 2.31$ (d, $J=15 \mathrm{~Hz}, 1 \mathrm{H}, 3-\mathrm{He}), 2.02$ $(\mathrm{d}, J=15 \mathrm{~Hz}, 1 \mathrm{H}, 6-\mathrm{He}), 1.91-1.85(\mathrm{~m}, 1 \mathrm{H}), 1.82-1.68(\mathrm{~m}, 4 \mathrm{H}), 1.63-1.60(\mathrm{~m}, 3 \mathrm{H}), 1.55-1.49(\mathrm{~m}, 4 \mathrm{H})$, $1.44-1.40(\mathrm{~m}, 1 \mathrm{H}), 1.35\left(\mathrm{~s}, 3 \mathrm{H}, 18-\mathrm{CH}_{3}\right), 1.27-1.22(\mathrm{~m}, 3 \mathrm{H}), 1.20-1.13(\mathrm{~m}, 1 \mathrm{H}), 0.98\left(\mathrm{~s}, 3 \mathrm{H}, 17-\mathrm{CH}_{3}\right), 0.73(\mathrm{~s}$, $\left.3 \mathrm{H}, 20-\mathrm{CH}_{3}\right) .{ }^{13} \mathrm{C}-\mathrm{NMR}\left(\mathrm{CDCl}_{3}, 75 \mathrm{MHz}, \mathrm{ppm}\right): \delta 222.03,175.62,165.27,133.74,129.12,127.95,125.25$, $122.65,121.67,63.41,57.10,54.73,54.23,48.67,48.39,44.06,41.31,39.59,39.40,38.02,37.98,37.22,29.01$, 21.97, 20.33, 19.83, 19.08, 13.43. HRMS $(m / z)$ : calcd for $\mathrm{C}_{28} \mathrm{H}_{37} \mathrm{ClNO}_{4}{ }^{+}[\mathrm{M}+\mathrm{H}]^{+}: 486.2406$, found: 486.2401 .

2-((3-chlorophenyl)amino)-2-oxoethyl(4R,4aS,6aR,9S,11aR,11bS)-4,9,11b-trimethyl-8-oxotetradecahydro-6a, 9-methanocyclohepta[a]naphthalene-4-carboxylate (4c). White powder; yield, 80\%; m.p. $120-122{ }^{\circ} \mathrm{C}$; ${ }^{1} \mathrm{H}-\mathrm{NMR}\left(\mathrm{CDCl}_{3}, 500 \mathrm{MHz}, \mathrm{ppm}\right): \delta 7.80$ (s, 1H, -CO-NH-), 7.60 (s, $\left.1 \mathrm{H}, \mathrm{Ar}-\mathrm{H}\right), 7.36(\mathrm{~d}, J=5 \mathrm{~Hz}, 1 \mathrm{H}$, Ar-H), 7.31-7.28 (m, 1H, Ar-H), $7.14(\mathrm{t}, J=5 \mathrm{~Hz}, 1 \mathrm{H}, \mathrm{Ar}-\mathrm{H}), 4.74(\mathrm{~d}, J=15 \mathrm{~Hz}, 1 \mathrm{H},-\mathrm{O}-\mathrm{CHe}-\mathrm{CO}-), 4.57$ (d, $J=15 \mathrm{~Hz}, 1 \mathrm{H},-\mathrm{O}-\mathrm{CHa}-\mathrm{CO}-), 2.61$ (dd, $J=20,5 \mathrm{~Hz}, 1 \mathrm{H}, 15-\mathrm{He}$ ), 2.27 (d, $J=15 \mathrm{~Hz}, 1 \mathrm{H}, 3-\mathrm{He}), 2.00$ $(\mathrm{d}, J=10 \mathrm{~Hz}, 1 \mathrm{H}, 6-\mathrm{He}), 1.87-1.71(\mathrm{~m}, 5 \mathrm{H}), 1.63-1.53(\mathrm{~m}, 5 \mathrm{H}), 1.45-1.38(\mathrm{~m}, 2 \mathrm{H}), 1.33\left(\mathrm{~s}, 3 \mathrm{H}, 18-\mathrm{CH}_{3}\right)$, $1.26-1.21(\mathrm{~m}, 3 \mathrm{H}), 1.20-1.13(\mathrm{~m}, 1 \mathrm{H}), 0.98\left(\mathrm{~s}, 3 \mathrm{H}, 17-\mathrm{CH}_{3}\right), 0.95-0.84(\mathrm{~m}, 1 \mathrm{H}), 0.73\left(\mathrm{~s}, 3 \mathrm{H}, 20-\mathrm{CH}_{3}\right)$. ${ }^{13} \mathrm{C}-\mathrm{NMR}\left(\mathrm{CDCl}_{3}, 75 \mathrm{MHz}, \mathrm{ppm}\right): \delta 222.02,175.84,165.17,137.98,134.86,130.21,124.98,119.83,117.67$, $63.28,56.99,54.70,54.18,48.69,48.40,44.04,41.36,39.59,39.43,38.06,37.97,37.20,28.99,21.99,20.33$, 19.81, 18.92, 13.50. HRMS $(m / z)$ : calcd for $\mathrm{C}_{28} \mathrm{H}_{37} \mathrm{ClNO}_{4}{ }^{+}[\mathrm{M}+\mathrm{H}]^{+}: 486.2406$, found: 486.2403.

2-((4-chlorophenyl)amino)-2-oxoethyl(4R,4aS,6aR,9S,11aR,11bS)-4,9,11b-trimethyl-8-oxotetradecahydro-6a, 9-methanocyclohepta[a]naphthalene-4-carboxylate (4d). White powder; yield, 84\%; m.p. $140-142{ }^{\circ} \mathrm{C}$; ${ }^{1} \mathrm{H}-\mathrm{NMR}\left(\mathrm{CDCl}_{3}, 500 \mathrm{MHz}, \mathrm{ppm}\right): \delta 7.80$ (s, 1H, -CO-NH-), 7.46 (d, J = $\left.5 \mathrm{~Hz}, 2 \mathrm{H}, \mathrm{Ar}-\mathrm{H}\right), 7.32-7.30$ (m, 2H, Ar-H), 4.73 (d, J = 15 Hz, 1H, -O-CHe-CO-), 4.57 (d, J = 15 Hz, 1H, -O-CHa-CO-), 2.61 (dd, $J=20,5 \mathrm{~Hz}, 1 \mathrm{H}, 18-\mathrm{He}), 2.27(\mathrm{~d}, J=15 \mathrm{~Hz}, 1 \mathrm{H}, 3-\mathrm{He}), 2.00$ (d, $J=15 \mathrm{~Hz}, 1 \mathrm{H}, 6-\mathrm{He}), 1.84-1.69$ (m, $6 \mathrm{H}), 1.63-1.62(\mathrm{~m}, 2 \mathrm{H}), 1.56-1.52(\mathrm{~m}, 2 \mathrm{H}), 1.49-1.38(\mathrm{~m}, 2 \mathrm{H}), 1.32\left(\mathrm{~s}, 3 \mathrm{H}, 18-\mathrm{CH}_{3}\right), 1.26-1.23(\mathrm{~m}, 3 \mathrm{H})$, $1.20-1.13(\mathrm{~m}, 1 \mathrm{H}), 0.98-0.88(\mathrm{~m}, 4 \mathrm{H}), 0.73\left(\mathrm{~s}, 3 \mathrm{H}, 20-\mathrm{CH}_{3}\right) .{ }^{13} \mathrm{C}-\mathrm{NMR}\left(\mathrm{CDCl}_{3}, 75 \mathrm{MHz}, \mathrm{ppm}\right): \delta 221.95$, 175.84, 165.08, 135.42, 129.95, 129.25(2C), 120.94(2C), 63.33, 56.99, 54.69, 54.18, 48.69, 48.39, 44.03, $41.37,39.58,39.42,38.06,37.96,37.19,28.99,21.97,20.33,19.82,18.92,13.51$. HRMS $(m / z)$ : calcd for $\mathrm{C}_{28} \mathrm{H}_{37} \mathrm{ClNO}_{4}{ }^{+}[\mathrm{M}+\mathrm{H}]^{+}:$486.2406, found: 486.2401 .

2-((2-fluorophenyl)amino)-2-oxoethyl(4R,4aS,6aR,9S,11aR,11bS)-4,9,11b-trimethyl-8-oxotetradecahydro-6a, 9-methanocyclohepta[a]naphthalene-4-carboxylate (4e). White crystal; yield, 81\%; m.p. $168-169{ }^{\circ} \mathrm{C}$; ${ }^{1} \mathrm{H}-\mathrm{NMR}\left(\mathrm{CDCl}_{3}, 500 \mathrm{MHz}, \mathrm{ppm}\right): \delta 8.42-8.39$ (m, 1H, Ar-H), 8.18 (s, 1H, -CO-NH-), 7.18-7.10 (m, 3H, Ar-H), 4.78 (d, J = 15 Hz, 1H, -O-CHe-CO-), 4.60 (d, J = 15 Hz, 1H, -O-CHa-CO-), 2.61 (d, J = $20 \mathrm{~Hz}$, $1 \mathrm{H}, 15-\mathrm{He}), 2.28(\mathrm{~d}, J=15 \mathrm{~Hz}, 1 \mathrm{H}, 3-\mathrm{He}), 2.03(\mathrm{~d}, J=10 \mathrm{~Hz}, 1 \mathrm{H}, 6-\mathrm{He}), 1.89-1.71$ (m, 5H), 1.63-1.59 
(m, 2H), 1.54-1.51 (m, 2H), 1.44-1.38 (m, 2H), $1.33\left(\mathrm{~s}, 3 \mathrm{H}, 18-\mathrm{CH}_{3}\right), 1.26-1.23(\mathrm{~m}, 4 \mathrm{H}), 1.18-1.13(\mathrm{~m}$, $1 \mathrm{H}), 0.99\left(\mathrm{~s}, 3 \mathrm{H}, 17-\mathrm{CH}_{3}\right), 0.94-0.84(\mathrm{~m}, 1 \mathrm{H}), 0.74\left(\mathrm{~s}, 3 \mathrm{H}, 20-\mathrm{CH}_{3}\right) .{ }^{13} \mathrm{C}-\mathrm{NMR}\left(\mathrm{CDCl}_{3}, 75 \mathrm{MHz}, \mathrm{ppm}\right)$ : $\delta 222.03,175.64,165.16,125.58,124.92,124.84,121.43,114.95,114.70,63.28,56.95,54.74,54.21,48.68$, $48.36,44.05,41.35,39.64,39.43,38.05(2 \mathrm{C}), 37.21,28.04,22.00,20.34,19.83,18.84,13.40$. HRMS $(\mathrm{m} / \mathrm{z})$ : calcd for $\mathrm{C}_{28} \mathrm{H}_{37} \mathrm{FNO}_{4}{ }^{+}[\mathrm{M}+\mathrm{H}]^{+}: 470.2701$, found: 470.2704 .

2-((3-fluorophenyl)amino)-2-oxoethyl(4R,4aS,6aR,9S,11aR,11bS)-4,9,11b-trimethyl-8-oxotetradecahydro-6a, 9-methanocyclohepta[a]naphthalene-4-carboxylate (4f). White powder; yield, 80\%; m.p. $144-145{ }^{\circ} \mathrm{C}$; ${ }^{1} \mathrm{H}-\mathrm{NMR}\left(\mathrm{CDCl}_{3}, 500 \mathrm{MHz}, \mathrm{ppm}\right): \delta 7.84(\mathrm{~s}, 1 \mathrm{H},-\mathrm{CO}-\mathrm{NH}-), 7.47$ (d, J = $\left.10 \mathrm{~Hz}, 1 \mathrm{H}, \mathrm{Ar}-\mathrm{H}\right), 7.31-7.28$ (m, $1 \mathrm{H}, \mathrm{Ar}-\mathrm{H}), 7.13(\mathrm{~d}, J=5 \mathrm{~Hz}, 1 \mathrm{H}, \mathrm{Ar}-\mathrm{H}), 6.88-6.84(\mathrm{~m}, 1 \mathrm{H}, \mathrm{Ar}-\mathrm{H}), 4.74$ (d, $J=15 \mathrm{~Hz}, 1 \mathrm{H},-\mathrm{O}-\mathrm{CHe}-\mathrm{CO}-)$, 4.58 (d, $J=15 \mathrm{~Hz}, 1 \mathrm{H},-\mathrm{O}-\mathrm{CHa}-\mathrm{CO}-), 2.61$ (dd, $J=20,5 \mathrm{~Hz}, 1 \mathrm{H}, 18-\mathrm{He}), 2.27$ (d, $J=15 \mathrm{~Hz}, 1 \mathrm{H}, 3-\mathrm{He})$, $2.01(\mathrm{~d}, J=15 \mathrm{~Hz}, 1 \mathrm{H}, 6-\mathrm{He}), 1.87-1.69(\mathrm{~m}, 5 \mathrm{H}), 1.63-1.61(\mathrm{~m}, 1 \mathrm{H}), 1.54-1.52(\mathrm{~m}, 5 \mathrm{H}), 1.43(\mathrm{dd}, J=9$, $3 \mathrm{~Hz}, 1 \mathrm{H}), 1.40-1.35(\mathrm{~m}, 1 \mathrm{H}), 1.33(\mathrm{~s}, 2 \mathrm{H}), 1.27-1.20(\mathrm{~m}, 3 \mathrm{H}), 1.19-1.13(\mathrm{~m}, 1 \mathrm{H}), 0.98\left(\mathrm{~s}, 3 \mathrm{H}, 17-\mathrm{CH}_{3}\right)$, 0.95-0.86 (m, 1H), $0.73\left(\mathrm{~s}, 3 \mathrm{H}, 20-\mathrm{CH}_{3}\right) .{ }^{13} \mathrm{C}-\mathrm{NMR}\left(\mathrm{CDCl}_{3}, 75 \mathrm{MHz}, \mathrm{ppm}\right): \delta 221.98,175.81,165.14$, 164.65, 138.32, 130.31, 114.84, 111.67, 107.31, 63.30, 56.98, 54.69, 54.17, 48.69, 48.39, 44.03, 41.36, 39.58, $39.42,38.06,37.96,37.19,28.98,21.99,20.32,19.81,18.92,13.50$. HRMS $(m / z)$ : calcd for $\mathrm{C}_{28} \mathrm{H}_{37} \mathrm{FNO}_{4}{ }^{+}$ $[\mathrm{M}+\mathrm{H}]^{+}: 470.2701$, found: 470.2699 .

2-((4-fluorophenyl)amino)-2-oxoethyl(4R,4aS,6aR,9S,11aR,11bS)-4,9,11b-trimethyl-8-oxotetradecahydro-6a, 9-methanocyclohepta[a]naphthalene-4-carboxylate (4g). White powder; yield, 90\%; m.p. $140-141{ }^{\circ} \mathrm{C}$; ${ }^{1} \mathrm{H}-\mathrm{NMR}\left(\mathrm{CDCl}_{3}, 500 \mathrm{MHz}, \mathrm{ppm}\right): \delta 7.76$ (s, 1H, -CO-NH-), 7.48-7.45 (m, 2H, Ar-H), 7.05 (t, J = $10 \mathrm{~Hz}$, 2H, Ar-H), 4.74 (d, J = 15 Hz, 1H, -O-CHe-CO-), 4.58 (d, J = 15 Hz, 1H, -O-CHa-CO-), 2.61 (d, J = 20 Hz, $1 \mathrm{H}, 18-\mathrm{He}), 2.27(\mathrm{~d}, J=15 \mathrm{~Hz}, 1 \mathrm{H}, 3-\mathrm{He}), 2.00(\mathrm{~d}, J=15 \mathrm{~Hz}, 1 \mathrm{H}, 6-\mathrm{He}), 1.87-1.70(\mathrm{~m}, 5 \mathrm{H}), 1.63-1.61(\mathrm{~m}$, 2H), 1.55-1.52 (m, 3H), 1.44-1.36 (m, 2H), $1.33(\mathrm{~s}, 3 \mathrm{H}), 1.26-1.23(\mathrm{~m}, 3 \mathrm{H}), 1.19-1.13(\mathrm{~m}, 1 \mathrm{H}), 0.98(\mathrm{~s}, 3 \mathrm{H})$, 0.95-0.86 (m, 1H), $0.73\left(\mathrm{~s}, 3 \mathrm{H}, 20-\mathrm{CH}_{3}\right) .{ }^{13} \mathrm{C}-\mathrm{NMR}\left(\mathrm{CDCl}_{3}, 75 \mathrm{MHz}, \mathrm{ppm}\right): \delta 222.01,175.86,165.06$, $161.29,132.87,121.63,121.53,116.06,115.75,63.29,56.99,54.69,54.18,48.69,48.40,44.02,41.37,39.59$, $39.42,38.06,37.96,37.19,28.99,21.96,20.32,19.82,18.92,13.51$. HRMS $(m / z)$ : calcd for $\mathrm{C}_{28} \mathrm{H}_{37} \mathrm{FNO}_{4}{ }^{+}$ $[\mathrm{M}+\mathrm{H}]^{+}: 470.2701$, found: 470.2707 .

2-((4-nitrophenyl)amino)-2-oxoethyl(4R,4aS,6aR,9S,11aR,11bS)-4,9,11b-trimethyl-8-oxotetradecahydro-6a, 9-methanocyclohepta[a]naphthalene-4-carboxylate (4h). Pale yellow solid; yield, 78\%; m.p. $189-190{ }^{\circ} \mathrm{C}$; ${ }^{1} \mathrm{H}-\mathrm{NMR}\left(\mathrm{CDCl}_{3}, 500 \mathrm{MHz}, \mathrm{ppm}\right): \delta 8.24(\mathrm{~d}, J=10 \mathrm{~Hz}, 2 \mathrm{H}, \mathrm{Ar}-\mathrm{H}), 8.08$ (s, 1H, -CO-NH-), 7.69 (d, $J=10 \mathrm{~Hz}, 2 \mathrm{H}, \mathrm{Ar}-\mathrm{H}), 4.77$ (d, J = 15 Hz, 1H, -O-CHe-CO-), 4.62 (d, J = $15 \mathrm{~Hz}, 1 \mathrm{H},-\mathrm{O}-\mathrm{CHa}-\mathrm{CO}-), 2.60$ (d, $J=20 \mathrm{~Hz}, 1 \mathrm{H}, 18-\mathrm{He}), 2.27(\mathrm{~d}, J=10 \mathrm{~Hz}, 1 \mathrm{H}, 3-\mathrm{He}), 2.00(\mathrm{~d}, J=15 \mathrm{~Hz}, 1 \mathrm{H}, 6-\mathrm{He}), 1.83-1.76(\mathrm{~m}, 3 \mathrm{H})$, $1.74-1.70(\mathrm{~m}, 2 \mathrm{H}), 1.63-1.59(\mathrm{~m}, 2 \mathrm{H}), 1.45-1.37(\mathrm{~m}, 3 \mathrm{H}), 1.34(\mathrm{~s}, 3 \mathrm{H}), 1.30(\mathrm{~s}, 1 \mathrm{H}), 1.23-1.10(\mathrm{~m}, 4 \mathrm{H}), 0.98$ (s, 3H), 0.95-0.84 (m, 2H), $0.73\left(\mathrm{~s}, 3 \mathrm{H}, 20-\mathrm{CH}_{3}\right) .{ }^{13} \mathrm{C}-\mathrm{NMR}\left(\mathrm{CDCl}_{3}, 125 \mathrm{MHz}, \mathrm{ppm}\right): \delta 222.00,175.99$, $165.48,144.11,142.50,125.27(2 \mathrm{C}), 119.17(2 \mathrm{C}), 63.42,56.99,54.69,54.18,48.70,48.41,44.10,41.36,39.55$, $39.44,38.08,37.97,37.19,29.01,21.98,20.34,19.81,18.94,13.55$. HRMS $(m / z)$ : calcd for $\mathrm{C}_{28} \mathrm{H}_{37} \mathrm{~N}_{2} \mathrm{O}_{6}{ }^{+}$ $[\mathrm{M}+\mathrm{H}]^{+}: 497.2646$, found: 497.2640 .

2-((4-methoxyphenyl)amino)-2-oxoethyl(4R,4aS,6aR,9S,11aR,11bS)-4,9,11b-trimethyl-8-oxotetradecahydro6a,9-methanocyclohepta[a]naphthalene-4-carboxylate (4i). White powder; yield, 81\%; m.p. 86-88 ${ }^{\circ} \mathrm{C}$; ${ }^{1} \mathrm{H}-\mathrm{NMR}\left(\mathrm{CDCl}_{3}, 500 \mathrm{MHz}, \mathrm{ppm}\right): \delta 7.70$ (s, 1H, -CO-NH-), 7.40 (d, J = 15 Hz, 2H, Ar-H), 6.88 (d, $J=10 \mathrm{~Hz}, 2 \mathrm{H}, \mathrm{Ar}-\mathrm{H}$ ), 4.73 (d, J = $15 \mathrm{~Hz}, 1 \mathrm{H},-\mathrm{O}-\mathrm{CHe}-\mathrm{CO}-), 4.57$ (d, J = $15 \mathrm{~Hz}, 1 \mathrm{H},-\mathrm{O}-\mathrm{CHa}-\mathrm{CO}-), 3.80$ (s, $\left.3 \mathrm{H}, \mathrm{ph}-\mathrm{O}-\mathrm{CH}_{3}\right), 2.62(\mathrm{~d}, J=15 \mathrm{~Hz}, 1 \mathrm{H}, 18-\mathrm{He}), 2.27(\mathrm{~d}, J=15 \mathrm{~Hz}, 1 \mathrm{H}, 3-\mathrm{He}), 2.00(\mathrm{~d}, J=10 \mathrm{~Hz}, 1 \mathrm{H}$, 6-He), $1.88-1.70(\mathrm{~m}, 5 \mathrm{H}), 1.63-1.58(\mathrm{~m}, 3 \mathrm{H}), 1.56-1.52(\mathrm{~m}, 2 \mathrm{H}), 1.44-1.39(\mathrm{~m}, 2 \mathrm{H}), 1.32\left(\mathrm{~s}, 3 \mathrm{H}, 18-\mathrm{CH}_{3}\right)$, $1.25-1.23(\mathrm{~m}, 3 \mathrm{H}), 1.18-1.12(\mathrm{~m}, 1 \mathrm{H}), 0.98(\mathrm{~s}, 3 \mathrm{H}), 0.94-0.88(\mathrm{~m}, 1 \mathrm{H}), 0.74\left(\mathrm{~s}, 3 \mathrm{H}, 20-\mathrm{CH}_{3}\right) .{ }^{13} \mathrm{C}-\mathrm{NMR}$ (CDCl $3,75 \mathrm{MHz}, \mathrm{ppm}): \delta 222.01,175.81,164.88,156.85,129.90,121.60(2 \mathrm{C}), 114.35(2 \mathrm{C}), 63.35,57.01$, 55.52, 54.71, 54.20, 48.70, 48.39, 44.02, 41.39, 39.61, 39.42, 38.05, 37.98, 37.20, 28.99, 21.98, 20.33, 19.81, 18.93, 13.50. HRMS $(m / z)$ : calcd for $\mathrm{C}_{29} \mathrm{H}_{40} \mathrm{NO}_{5}{ }^{+}[\mathrm{M}+\mathrm{H}]^{+}:$482.2901, found: 482.2905 .

2-((2,5-dimethoxyphenyl)amino)-2-oxoethyl(4R,4aS,6aR,9S,11aR,11bS)-4,9,11b-trimethyl-8-oxotetradecahydro6a,9-methanocyclohepta[a]naphthalene-4-carboxylate (4j). White powder; yield, 79\%; m.p. $166-168{ }^{\circ} \mathrm{C}$; 
${ }^{1} \mathrm{H}-\mathrm{NMR}\left(\mathrm{CDCl}_{3}, 500 \mathrm{MHz}, \mathrm{ppm}\right): \delta 8.55$ (s, 1H, -CO-NH-), $8.14(\mathrm{~d}, J=3 \mathrm{~Hz}, 1 \mathrm{H}, \mathrm{Ar}-\mathrm{H}), 6.81$ (d, $J=5 \mathrm{~Hz}, 1 \mathrm{H}, \mathrm{Ar}-\mathrm{H}), 6.61$ (dd, $J=10,5 \mathrm{~Hz}, 1 \mathrm{H}, \mathrm{Ar}-\mathrm{H}), 4.80$ (d, J = $15 \mathrm{~Hz}, 1 \mathrm{H},-\mathrm{O}-\mathrm{CHe}-\mathrm{CO}-), 4.54$ (d, $J=15 \mathrm{~Hz}, 1 \mathrm{H},-\mathrm{O}-\mathrm{CHa}-\mathrm{CO}-), 3.83\left(\mathrm{~s}, 3 \mathrm{H}, \mathrm{ph}-\mathrm{O}-\mathrm{CH}_{3}\right), 3.79\left(\mathrm{~s}, 3 \mathrm{H}, \mathrm{ph}-\mathrm{O}-\mathrm{CH}_{3}\right), 2.61(\mathrm{dd}, J=15,5 \mathrm{~Hz}, 1 \mathrm{H}$, 18-He), $2.31(\mathrm{~d}, J=15 \mathrm{~Hz}, 1 \mathrm{H}, 3-\mathrm{He}), 2.01(\mathrm{~d}, J=15 \mathrm{~Hz}, 1 \mathrm{H}, 6-\mathrm{He}), 1.88(\mathrm{qt}, J=9,3 \mathrm{~Hz}, 1 \mathrm{H}) 1.82-1.74(\mathrm{~m}$, $3 \mathrm{H}), 1.71-1.67(\mathrm{~m}, 2 \mathrm{H}), 1.63-1.60(\mathrm{~m}, 1 \mathrm{H}), 1.55-1.47(\mathrm{~m}, 3 \mathrm{H}), 1.44-1.37(\mathrm{~m}, 2 \mathrm{H}), 1.35\left(\mathrm{~s}, 3 \mathrm{H}, 18-\mathrm{CH}_{3}\right)$, 1.27-1.22 (m, 3H), 1.18-1.10 (m, $1 \mathrm{H}), 0.98-0.93(\mathrm{~m}, 4 \mathrm{H}), 0.73\left(\mathrm{~s}, 3 \mathrm{H}, 20-\mathrm{CH}_{3}\right) .{ }^{13} \mathrm{C}-\mathrm{NMR}\left(\mathrm{CDCl}_{3}, 75\right.$ MHz, ppm): $\delta 222.00,175.50,164.97,153.94,142.05,127.36,110.68,109.07,106.08,63.14,57.09,56.04$, $55.83,54.74,54.24,48.66,48.39,43.99,41.39,39.63,39.41,38.02,37.88,37.22,28.83,21.76,20.32,19.83$, 18.96, 13.38. HRMS $(m / z)$ : calcd for $\mathrm{C}_{30} \mathrm{H}_{42} \mathrm{NO}_{6}{ }^{+}[\mathrm{M}+\mathrm{H}]^{+}:$512.3007, found: 512.3001 .

\subsection{General Procedure for the Synthesis of Compound (5a-5e)}

A mixture of isosteviol $(63.6 \mathrm{mg}, 0.20 \mathrm{mmol}), \mathrm{K}_{2} \mathrm{CO}_{3}(41.5 \mathrm{mg}, 0.30 \mathrm{mmol})$ and different phenyl 1,2,3-triazole chloroacetamides $(0.21 \mathrm{mmol})$ in $\mathrm{CH}_{3} \mathrm{CN}(10 \mathrm{~mL})$ was stirred at $80{ }^{\circ} \mathrm{C}$ for $2 \mathrm{~h}$. After confirming the reaction progress by thin-layer chromatography, the solvent was evaporated in vacuo, the mixture was dissolved with $15 \mathrm{~mL}$ ethyl acetate and then washed with saline $(5 \mathrm{~mL} \times 3)$. The mixture was then purified using silica gel column chromatography and eluted with petroleum ether:ethyl acetate (1:1) to obtain the target compound $5 \mathbf{a}-\mathbf{5 e}$.

2-oxo-2-(((1-phenyl-1H-1,2,3-triazol-4-yl)methyl)amino)ethyl(4R,4aS,6aR,9S,11aR,11bS)-4,9,11b-trimethyl -8-oxotetradecahydro-6a,9-methanocyclohepta[a]naphthalene-4-carboxylate (5a). White solid; yield, 81\%; m.p. 83-84 ${ }^{\circ} \mathrm{C} ;{ }^{1} \mathrm{H}-\mathrm{NMR}\left(\mathrm{CDCl}_{3}, 300 \mathrm{MHz}, \mathrm{ppm}\right): \delta 8.01(\mathrm{~s}, 1 \mathrm{H}$, triazole-H), 7.74-7.71 (m, 2H, Ar-H), 7.56-7.42 (m, 3H, Ar-H), 6.91 (brs, 1H, -NH-CO-), 4.74-4.46 (m, 4H, -O- $\left.\mathrm{CH}_{2-}^{-},-\mathrm{CH}_{2}-\mathrm{NH}-\right), 2.56$ (dd, $J=18,3 \mathrm{~Hz}, 1 \mathrm{H}, 15-\mathrm{He}), 2.22(\mathrm{~d}, J=12 \mathrm{~Hz}, 1 \mathrm{H}, 3-\mathrm{He}), 1.95(\mathrm{~d}, J=12 \mathrm{~Hz}, 1 \mathrm{H}, 6-\mathrm{He}), 1.85-1.66(\mathrm{~m}, 6 \mathrm{H})$, $1.62-1.47(\mathrm{~m}, 4 \mathrm{H}), 1.42-1.37(\mathrm{~m}, 2 \mathrm{H}), 1.27\left(\mathrm{~s}, 3 \mathrm{H}, 18-\mathrm{CH}_{3}\right), 1.20-1.13(\mathrm{~m}, 3 \mathrm{H}), 1.10-1.04(\mathrm{~m}, 1 \mathrm{H}), 0.96$ $\left(\mathrm{s}, 3 \mathrm{H}, 17-\mathrm{CH}_{3}\right), 0.93-0.88(\mathrm{~m}, 1 \mathrm{H}), 0.67\left(\mathrm{~s}, 3 \mathrm{H}, 20-\mathrm{CH}_{3}\right) .{ }^{13} \mathrm{C}-\mathrm{NMR}\left(\mathrm{CDCl}_{3}, 75 \mathrm{MHz}, \mathrm{ppm}\right): \delta 222.09$, 176.00, 167.37, 144.64, 136.87, 129.81(2C), 128.93, 120.52(2C), 120.44, 62.98, 56.98, 54.66, 54.17, 48.64, $48.31,43.95,41.28,39.61,39.39,37.99,37.94,37.20,34.69,28.91,21.90,20.29,19.82,18.87,13.42$. HRMS $(m / z)$ : calcd for $\mathrm{C}_{31} \mathrm{H}_{41} \mathrm{~N}_{4} \mathrm{O}_{4}{ }^{+}[\mathrm{M}+\mathrm{H}]^{+}$: 533.3122, found: 533.3119 .

2-(((1-(4-chlorophenyl)-1H-1,2,3-triazol-4-yl)methyl)amino)-2-oxoethyl(4R,4aS,6aR,9S,11aR,11bS)-4,9,11b -trimethyl-8-oxotetradecahydro-6a,9-methanocyclohepta[a]naphthalene-4-carboxylate (5b). White solid; yield, 82\%; m.p. 80-82 ${ }^{\circ} \mathrm{C} ;{ }^{1} \mathrm{H}-\mathrm{NMR}\left(\mathrm{CDCl}_{3}, 300 \mathrm{MHz}, \mathrm{ppm}\right): \delta 8.00(\mathrm{~s}, 1 \mathrm{H}$, triazole-H), 7.71-7.68 $(\mathrm{m}, 2 \mathrm{H}$, Ar-H), 7.54-7.51 (m, 2H, Ar-H), 6.81 (brs, 1H, -NH-CO-), 4.74-4.47 (m, 4H, -O- $\left.\mathrm{CH}_{2-}^{-},-\mathrm{C}_{2}-\mathrm{NH}-\right), 2.57$ $(\mathrm{dd}, J=18,3 \mathrm{~Hz}, 1 \mathrm{H}, 15-\mathrm{He}), 2.23(\mathrm{~d}, J=12 \mathrm{~Hz}, 1 \mathrm{H}, 3-\mathrm{He}), 1.96(\mathrm{~d}, J=12 \mathrm{~Hz}, 1 \mathrm{H}, 6-\mathrm{He}), 1.82-1.68(\mathrm{~m}$, $6 \mathrm{H}), 1.60-1.39(\mathrm{~m}, 6 \mathrm{H}), 1.28\left(\mathrm{~s}, 3 \mathrm{H}, 18-\mathrm{CH}_{3}\right), 1.22-1.15(\mathrm{~m}, 3 \mathrm{H}), 1.12-1.06(\mathrm{~m}, 1 \mathrm{H}), 0.99\left(\mathrm{~s}, 3 \mathrm{H}, 17-\mathrm{CH}_{3}\right)$, 0.95-0.87 (m, 1H), 0.68 (s, 3H, 20- $\left.\mathrm{CH}_{3}\right) .{ }^{13} \mathrm{C}-\mathrm{NMR}\left(\mathrm{CDCl}_{3}, 75 \mathrm{MHz}, \mathrm{ppm}\right): \delta 222.09,176.02,167.44$, 144.90, 135.35, 134.76, 130.01(2C), 121.69(2C), 120.44, 62.99, 56.98, 54.67, 54.18, 48.66, 48.33, 43.96, 41.30, $39.61,39.40,38.00,37.94,37.21,34.64,28.91,21.91,20.30,19.82,18.87,13.42$. HRMS $(m / z)$ : calcd for $\mathrm{C}_{31} \mathrm{H}_{40} \mathrm{ClN}_{4} \mathrm{O}_{4}{ }^{+}[\mathrm{M}+\mathrm{H}]^{+}:$567.2733, found: 567.2729.

2-(((1-(4-methoxyphenyl)-1H-1,2,3-triazol-4-yl)methyl)amino)-2-oxoethyl(4R,4aS,6aR,9S,11aR,11bS)-4,9, 11b-trimethyl-8-oxotetradecahydro-6a,9-methanocyclohepta[a]naphthalene-4-carboxylate (5c). White solid; yield, 83\%; m.p. $71-72{ }^{\circ} \mathrm{C}$; ${ }^{1} \mathrm{H}-\mathrm{NMR}\left(\mathrm{CDCl}_{3}, 300 \mathrm{MHz}, \mathrm{ppm}\right): \delta 7.92(\mathrm{~s}, 1 \mathrm{H}$, triazole-H), $7.62(\mathrm{~d}$, $J=6 \mathrm{~Hz}, 2 \mathrm{H}, \mathrm{Ar}-\mathrm{H}), 7.04$ (d, $J=6 \mathrm{~Hz}, 2 \mathrm{H}, \mathrm{Ar}-\mathrm{H}), 6.87$ (brs, $1 \mathrm{H},-\mathrm{NH}-\mathrm{CO}-), 4.74-4.47$ (m, 4H, -O- $\mathrm{CH}_{2-}$, $\left.-\mathrm{CH}_{2}-\mathrm{NH}-\right), 3.88\left(\mathrm{~s}, 3 \mathrm{H},-\mathrm{O}-\mathrm{CH}_{3}\right), 2.57(\mathrm{dd}, J=18,3 \mathrm{~Hz}, 1 \mathrm{H}, 15-\mathrm{He}), 2.23(\mathrm{~d}, J=12 \mathrm{~Hz}, 1 \mathrm{H}, 3-\mathrm{He}), 1.96$ $(\mathrm{d}, J=12 \mathrm{~Hz}, 1 \mathrm{H}, 6-\mathrm{He}), 1.80-1.68(\mathrm{~m}, 6 \mathrm{H}), 1.62-1.48(\mathrm{~m}, 4 \mathrm{H}), 1.45-1.38(\mathrm{~m}, 3 \mathrm{H}), 1.23-1.19(\mathrm{~m}, 3 \mathrm{H})$, 1.16-1.05 (m, 2H), $0.98\left(\mathrm{~s}, 3 \mathrm{H}, 17-\mathrm{CH}_{3}\right), 0.94-0.87(\mathrm{~m}, 2 \mathrm{H}), 0.68\left(\mathrm{~s}, 3 \mathrm{H}, 20-\mathrm{CH}_{3}\right) .{ }^{13} \mathrm{C}-\mathrm{NMR}\left(\mathrm{CDCl}_{3}, 75\right.$ MHz, ppm): $\delta$ 222.11, 175.97, 167.33, 159.95, 144.37, 130.30, 122.18(2C), 120.55, 114.84(2C), 63.00, 56.98, $55.64,54.67,54.17,48.65,48.30,43.95,41.28,39.61,39.39,38.00,37.94,37.21,34.70,28.91,21.92,20.29$, 19.82, 18.87, 13.41. HRMS $(m / z)$ : calcd for $\mathrm{C}_{32} \mathrm{H}_{43} \mathrm{~N}_{4} \mathrm{O}_{5}{ }^{+}[\mathrm{M}+\mathrm{H}]^{+}: 563.3228$, found: 563.3225. 
2-oxo-2-(((1-(p-tolyl)-1H-1,2,3-triazol-4-yl)methyl)amino)ethyl(4R,4aS,6aR,9S,11aR,11bS)-4,9,11b-trimethyl -8-oxotetradecahydro-6a,9-methanocyclohepta[a]naphthalene-4-carboxylate (5d). White solid; yield, 83\%; m.p. 66-68 ${ }^{\circ} \mathrm{C} ;{ }^{1} \mathrm{H}-\mathrm{NMR}\left(\mathrm{CDCl}_{3}, 300 \mathrm{MHz}, \mathrm{ppm}\right): \delta 7.96(\mathrm{~s}, 1 \mathrm{H}$, triazole-H), $7.60(\mathrm{~d}, J=9 \mathrm{~Hz}, 2 \mathrm{H}, \mathrm{Ar}-\mathrm{H})$, 7.33 (d, J = 9 Hz, 2H, Ar-H), 6.84 (brs, 1H, -NH-CO-), 4.74-4.47 (m, 4H, -O-CH $\left.2^{-},-\mathrm{CH}_{2}-\mathrm{NH}-\right), 2.56$ (dd, $J=21,3 \mathrm{~Hz}, 1 \mathrm{H}, 15-\mathrm{He}), 2.43\left(\mathrm{~s}, 3 \mathrm{H}, \mathrm{Ar}-\mathrm{CH}_{3}\right), 2.23(\mathrm{~d}, J=15 \mathrm{~Hz}, 1 \mathrm{H}, 3-\mathrm{He}), 1.95(\mathrm{~d}, J=12 \mathrm{~Hz}, 1 \mathrm{H}$, 6-He), $1.80-1.66(\mathrm{~m}, 6 \mathrm{H}), 1.62-1.48(\mathrm{~m}, 4 \mathrm{H}), 1.43-1.38(\mathrm{~m}, 2 \mathrm{H}), 1.28\left(\mathrm{~s}, 3 \mathrm{H}, 18-\mathrm{CH}_{3}\right), 1.21-1.15(\mathrm{~m}, 3 \mathrm{H})$, $1.10-1.05(\mathrm{~m}, 1 \mathrm{H}), 0.97\left(\mathrm{~s}, 3 \mathrm{H}, 17-\mathrm{CH}_{3}\right), 0.93-0.88(\mathrm{~m}, 1 \mathrm{H}), 0.68\left(\mathrm{~s}, 3 \mathrm{H}, 20-\mathrm{CH}_{3}\right) .{ }^{13} \mathrm{C}-\mathrm{NMR}\left(\mathrm{CDCl}_{3}, 75\right.$ MHz, ppm): $\delta$ 222.15, 175.97, 167.34, 144.42, 139.10, 134.58, 130.31(2C), 120.44(2C), 120.41, 62.99, 56.97, $54.66,54.16,48.65,48.30,43.94,41.27,39.60,39.38,37.99,37.94,37.20,34.71,28.92,21.91,21.11,20.29$, 19.83, 18.87, 13.41. HRMS ( $m / z)$ : calcd for $\mathrm{C}_{32} \mathrm{H}_{43} \mathrm{~N}_{4} \mathrm{O}_{4}{ }^{+}[\mathrm{M}+\mathrm{H}]^{+}: 547.3279$, found: 547.3276.

2-(((1-(3,4-dichlorophenyl)-1H-1,2,3-triazol-4-yl)methyl)amino)-2-oxoethyl(4R,4aS,6aR,9S,11aR,11bS)-4,9, 11b-trimethyl-8-oxotetradecahydro-6a,9-methanocyclohepta[a]naphthalene-4-carboxylate (5e). White solid; yield, 79\%; m.p. 96-97 ${ }^{\circ} \mathrm{C} ;{ }^{1} \mathrm{H}-\mathrm{NMR}\left(\mathrm{CDCl}_{3}, 300 \mathrm{MHz}, \mathrm{ppm}\right): \delta 8.02(\mathrm{~s}, 1 \mathrm{H}$, triazole-H), 7.92-7.91 (m, 1H, Ar-H), 7.65-7.59 (m, 2H, Ar-H), 6.81 (brs, $1 \mathrm{H},-\mathrm{NH}-\mathrm{CO}-)$, 4.73-4.47 (m, 4H, -O- $\left.\mathrm{CH}_{2-}^{-},-\mathrm{CH}_{2}-\mathrm{NH}-\right)$, $2.56(\mathrm{dd}, J=18,3 \mathrm{~Hz}, 1 \mathrm{H}, 15-\mathrm{He}), 2.23(\mathrm{~d}, J=15 \mathrm{~Hz}, 1 \mathrm{H}, 3-\mathrm{He}), 1.98-1.93(\mathrm{~m}, 1 \mathrm{H}, 6-\mathrm{He}), 1.82-1.67(\mathrm{~m}$, $6 \mathrm{H}), 1.63-1.47(\mathrm{~m}, 4 \mathrm{H}), 1.45-1.35(\mathrm{~m}, 2 \mathrm{H}), 1.28\left(\mathrm{~s}, 3 \mathrm{H}, 18-\mathrm{CH}_{3}\right), 1.22-1.15(\mathrm{~m}, 3 \mathrm{H}), 1.12-1.06(\mathrm{~m}, 1 \mathrm{H})$, $0.98\left(\mathrm{~s}, 3 \mathrm{H}, 17-\mathrm{CH}_{3}\right), 0.95-0.89(\mathrm{~m}, 1 \mathrm{H}), 0.69\left(\mathrm{~s}, 3 \mathrm{H}, 20-\mathrm{CH}_{3}\right) .{ }^{13} \mathrm{C}-\mathrm{NMR}\left(\mathrm{CDCl}_{3}, 75 \mathrm{MHz}, \mathrm{ppm}\right): \delta$ 222.08, 176.06, 167.50, 145.20, 135.87, 134.08, 133.07, 131.55, 122.26, 120.43, 119.39, 63.00, 56.98, 54.66, 54.19, 48.66, 48.34, 43.96, 41.31, 39.60, 39.40, 38.01, 37.94, 37.21, 34.64, 28.92, 21.89, 20.31, 19.82, 18.88, 13.44. HRMS $(m / z)$ : calcd for $\mathrm{C}_{31} \mathrm{H}_{39} \mathrm{Cl}_{2} \mathrm{~N}_{4} \mathrm{O}_{4}{ }^{+}[\mathrm{M}+\mathrm{H}]^{+}: 601.2343$, found: 601.2340.

\subsection{General Procedure for the Synthesis of Compound ( $6 \boldsymbol{a}-\mathbf{6 e})$}

A mixture of isosteviol $(63.6 \mathrm{mg}, 0.20 \mathrm{mmol}), \mathrm{K}_{2} \mathrm{CO}_{3}(41.5 \mathrm{mg}, 0.30 \mathrm{mmol})$ and different phosphonic acid [[(chloroacetyl) amino] phenylmethyl]-diethyl esters $(0.21 \mathrm{mmol})$ in $\mathrm{CH}_{3} \mathrm{CN}(10$ $\mathrm{mL}$ ) was stirred at $80^{\circ} \mathrm{C}$ for $3 \mathrm{~h}$. After confirming the reaction progress by thin-layer chromatography, the solvent was evaporated in vacuo, the mixture was dissolved with $15 \mathrm{~mL}$ ethyl acetate and then washed with saline $(5 \mathrm{~mL} \times 3)$. The mixture was then purified using silica gel column chromatography and eluted with a gradient of petroleum ether:ethyl acetate (3:1-1:1) to obtain the target compound 6a-6e.

2-((diethoxyphosphoryl)(phenyl)methyl)amino)-2-oxoethyl(4R,4aS,6aR,9S,11aR,11bS)-4,9,11b-trimethyl -8-oxotetradecahydro-6a,9-methanocyclohepta[a]naphthalene-4-carboxylate (6a). White powder; yield, 81\%; m.p. ${ }^{156-157}{ }^{\circ} \mathrm{C} ;{ }^{1} \mathrm{H}-\mathrm{NMR}\left(\mathrm{CDCl}_{3}, 300 \mathrm{MHz}, \mathrm{ppm}\right): \delta$ 7.41-7.35 (m, 5H, Ar-H), 7.20-7.12 (m, 1H, -NH-CO-), 5.48 (dd, J = 18, 9 Hz, 1H, -P-Cㅌ-NH-), 4.76-4.64 (m, 1H, -O-CHe-CO-), 4.53-4.40 (m, 1H, -O-CHa-CO-), 4.19-4.07 (m, 2H, -O-CHe-), 4.00-3.87 (m, 1H, -O-CHa-), 3.77-3.62 (m, 1H, -O-CHa-), 2.65-2.56 (m, 1H, 15-He), 2.27 (d, J = $15 \mathrm{~Hz}, 1 \mathrm{H}, 3-\mathrm{He}), 2.09-1.99(\mathrm{~m}, 1 \mathrm{H}, 6-\mathrm{He}), 1.89-1.69(\mathrm{~m}, 6 \mathrm{H})$, $1.65-1.50(\mathrm{~m}, 4 \mathrm{H}), 1.45-1.41(\mathrm{~m}, 2 \mathrm{H}), 1.35-1.29(\mathrm{~m}, 6 \mathrm{H}), 1.27-1.19(\mathrm{~m}, 3 \mathrm{H}), 1.15-1.07(\mathrm{~m}, 4 \mathrm{H}), 1.00-0.99$ $(\mathrm{m}, 3 \mathrm{H}), 0.95-0.87(\mathrm{~m}, 1 \mathrm{H}), 0.70\left(\mathrm{~s}, 3 \mathrm{H}, 20-\mathrm{CH}_{3}\right) .{ }^{13} \mathrm{C}-\mathrm{NMR}\left(\mathrm{CDCl}_{3}, 75 \mathrm{MHz}, \mathrm{ppm}\right): \delta 221.94,175.72$, 166.43, 134.77, 128.78(2C), 128.38, 127.91(2C), 63.60, 63.12, 62.74, 56.91, 54.73, 54.21, 50.82, 48.68, 48.40, $43.97,41.41,39.64,39.41,38.02(2 \mathrm{C}), 37.23,28.86,21.92,20.32,19.82,18.93,16.42,16.10,13.38$. HRMS $(m / z)$ : calcd for $\mathrm{C}_{33} \mathrm{H}_{49} \mathrm{NO}_{7} \mathrm{P}^{+}[\mathrm{M}+\mathrm{H}]^{+}: 602.3241$, found: 602.3238 .

2-(((4-chlorophenyl)(diethoxyphosphoryl)methyl)amino)-2-oxoethyl(4R,4aS,6aR,9S,11aR,11bS)-4,9,11btrimethyl-8-oxotetradecahydro-6a,9-methanocyclohepta[a]naphthalene-4-carboxylate (6b). White powder; yield, 83\%; m.p. $149-150{ }^{\circ} \mathrm{C} ;{ }^{1} \mathrm{H}-\mathrm{NMR}\left(\mathrm{CDCl}_{3}, 300 \mathrm{MHz}, \mathrm{ppm}\right): \delta$ 7.46-7.33 (m, 4H, Ar-H), 7.27-7.16 (m, 1H, -NH-CO-), 5.44 (ddd, J = 21, 9, 3 Hz, 1H, -P-C $(\mathrm{t}, J=15 \mathrm{~Hz}, 1 \mathrm{H},-\mathrm{O}-\mathrm{CHa}-\mathrm{CO}-), 4.18-4.09$ (m, 2H, -O-CHe-), 4.03-3.90 (m, 1H, -O-CHa-), 3.84-3.70 (m, $1 \mathrm{H},-\mathrm{O}-\mathrm{CHa}-), 2.60$ (d, $J=18 \mathrm{~Hz}, 1 \mathrm{H}, 15-\mathrm{He}), 2.25$ (d, $J=12 \mathrm{~Hz}, 1 \mathrm{H}, 3-\mathrm{He}), 2.05-1.98$ (m, 1H, 6-He), 1.89-1.65 (m, 7H), 1.60-1.53 (m, 3H), 1.45-1.40 (m, 2H), 1.35-1.29 (m, 6H), 1.26-1.22 (m, 4H), 1.16-1.11 $(\mathrm{m}, 3 \mathrm{H}), 1.00-0.99(\mathrm{~m}, 3 \mathrm{H}), 0.95-0.91(\mathrm{~m}, 1 \mathrm{H}), 0.70-0.69\left(\mathrm{~m}, 3 \mathrm{H}, 20-\mathrm{CH}_{3}\right) .{ }^{13} \mathrm{C}-\mathrm{NMR}\left(\mathrm{CDCl}_{3}, 75 \mathrm{MHz}\right.$, ppm): $\delta 221.99,175.77,166.59,134.39,133.40,129.30,129.19,128.99(2 \mathrm{C}), 63.72,63.30,62.78,56.96,54.72$, 
$54.21,50.31,48.68,48.41,43.97,41.36,39.64,39.41,38.02,37.98,37.22,28.89,21.99,20.32,19.82,18.92$, $16.45,16.16,13.38$. HRMS $(m / z)$ : calcd for $\mathrm{C}_{33} \mathrm{H}_{48} \mathrm{ClNO}_{7} \mathrm{P}^{+}[\mathrm{M}+\mathrm{H}]^{+}: 636.2851$, found: 636.2846.

2-(((diethoxyphosphoryl)(4-methoxyphenyl)methyl)amino)-2-oxoethyl(4R,4aS,6aR,9S,11aR,11bS)-4,9,11btrimethyl-8-oxotetradecahydro-6a,9-methanocyclohepta[a]naphthalene-4-carboxylate (6c). White powder; yield, 81\%; m.p. $134-135{ }^{\circ} \mathrm{C} ;{ }^{1} \mathrm{H}-\mathrm{NMR}\left(\mathrm{CDCl}_{3}, 300 \mathrm{MHz}, \mathrm{ppm}\right): \delta$ 7.37-7.34 (m, 2H, Ar-H), 7.17-7.15 (m, 1H, -NH-CO-), 6.91-6.87 (m, 2H, Ar-H), 5.48 (dd, J = 21, 9 Hz, 1H, -P-Cㅌ-NH-), 4.72-4.62 (m, 1H, -O-CHe-CO-), 4.51-4.39 (m, 1H, -O-CHe-CO-), 4.18-4.07 (m, 2H, -O-CHe-), 4.00-3.90 (m, 1H, -O-CHa-), $3.80\left(\mathrm{~s}, 3 \mathrm{H}, \mathrm{ph}-\mathrm{OCH}_{3}\right), 3.76-3.66(\mathrm{~m}, 1 \mathrm{H},-\mathrm{O}-\mathrm{CHa}-), 2.60(\mathrm{~d}, J=18 \mathrm{~Hz}, 1 \mathrm{H}, 15-\mathrm{He}), 2.25$ (d, J = $12 \mathrm{~Hz}$, $1 \mathrm{H}, 3-\mathrm{He}), 2.05-1.98(\mathrm{~m}, 1 \mathrm{H}, 6-\mathrm{He}), 1.88-1.73(\mathrm{~m}, 5 \mathrm{H}), 1.68-1.53(\mathrm{~m}, 5 \mathrm{H}), 1.44-1.40(\mathrm{~m}, 2 \mathrm{H}), 1.35-1.29$ $(\mathrm{m}, 6 \mathrm{H}), 1.26-1.17(\mathrm{~m}, 4 \mathrm{H}), 1.13-1.08(\mathrm{~m}, 3 \mathrm{H}), 0.99-0.98(\mathrm{~m}, 3 \mathrm{H}), 0.96-0.90(\mathrm{~m}, 1 \mathrm{H}), 0.69\left(\mathrm{~s}, 3 \mathrm{H}, 20-\mathrm{CH}_{3}\right)$. ${ }^{13} \mathrm{C}-\mathrm{NMR}\left(\mathrm{CDCl}_{3}, 75 \mathrm{MHz}, \mathrm{ppm}\right): \delta 221.86,175.71,166.29,159.63,129.24(2 \mathrm{C}), 126.75,114.19(2 \mathrm{C}), 63.57$, $62.98,62.75,56.92,55.31,54.73,54.21,50.14,48.67,48.40,43.96,41.41,39.64,39.42,38.02(2 \mathrm{C}), 37.21$, $28.86,21.95,20.32,19.82,18.93,16.39,16.24,13.31$. HRMS $(m / z)$ : calcd for $\mathrm{C}_{34} \mathrm{H}_{51} \mathrm{NO}_{8} \mathrm{P}^{+}[\mathrm{M}+\mathrm{H}]^{+}$: 632.3347, found: 632.3344 .

2-((diethoxyphosphoryl)(p-tolyl)methyl)amino)-2-oxoethyl(4R,4aS,6aR,9S,11aR,11bS)-4,9,11b-trimethyl8-oxotetradecahydro-6a,9-methanocyclohepta[a]naphthalene-4-carboxylate (6d). White powder; yield, 84\%; m.p. 119-120 ${ }^{\circ} \mathrm{C} ;{ }^{1} \mathrm{H}-\mathrm{NMR}\left(\mathrm{CDCl}_{3}, 300 \mathrm{MHz}, \mathrm{ppm}\right): \delta$ 7.32-7.29 (m, 2H, Ar-H), 7.18-7.11 (m, 3H, Ar-H, -NH-CO-), 5.44 (dd, J = 21, 9 Hz, 1H, -P-Cㅌ-NH-), 4.74-4.62 (m, 1H, -O-CHe-CO-), 4.51-4.38 (m, 1H, -O-CHe-CO-), 4.18-4.06 (m, 2H, -O-CHe-), 4.00-3.87 (m, 1H, -O-CHa-), 3.78-3.64 (m, 1H, -O-CHa-), $2.60(\mathrm{dq}, J=18,3 \mathrm{~Hz}, 1 \mathrm{H}, 15-\mathrm{He}), 2.34\left(\mathrm{~s}, 3 \mathrm{H}, \mathrm{ph}-\mathrm{CH}_{3}\right), 2.26(\mathrm{~d}, J=15 \mathrm{~Hz}, 1 \mathrm{H}, 3-\mathrm{He}), 2.07-1.99(\mathrm{~m}$, $1 \mathrm{H}, 6-\mathrm{He}), 1.89-1.78(\mathrm{~m}, 3 \mathrm{H}), 1.73-1.69(\mathrm{~m}, 3 \mathrm{H}), 1.64-1.54(\mathrm{~m}, 4 \mathrm{H}), 1.49-1.40(\mathrm{~m}, 3 \mathrm{H}), 1.35-1.29(\mathrm{~m}$, $6 \mathrm{H}), 1.26-1.22(\mathrm{~m}, 3 \mathrm{H}), 1.13-1.08(\mathrm{~m}, 3 \mathrm{H}), 1.00-0.99(\mathrm{~m}, 3 \mathrm{H}), 0.95-0.91(\mathrm{~m}, 1 \mathrm{H}), 0.69\left(\mathrm{~s}, 3 \mathrm{H}, 20-\mathrm{CH}_{3}\right)$. ${ }^{13} \mathrm{C}-\mathrm{NMR}\left(\mathrm{CDCl}_{3}, 75 \mathrm{MHz}, \mathrm{ppm}\right): \delta 221.98,175.68,166.28,138.26,131.68,129.48(2 \mathrm{C}), 127.86(2 \mathrm{C}), 63.48$, 63.08, 62.79, 57.00, 54.74, 54.24, 50.53, 48.68, 48.41, 43.97, 41.36, 39.65, 39.42, 38.02(2C), 37.24, 28.96, $22.16,21.14,20.32,19.82,18.95,16.42,16.13,13.30$. HRMS $(m / z)$ : calcd for $\mathrm{C}_{34} \mathrm{H}_{51} \mathrm{NO}_{7} \mathrm{P}^{+}[\mathrm{M}+\mathrm{H}]^{+}$: 616.3398, found: 616.3393 .

2-(((3,4-dichlorophenyl)(diethoxyphosphoryl)methyl)amino)-2-oxoethyl(4R,4aS,6aR,9S,11aR,11bS)-4,9,11b -trimethyl-8-oxotetradecahydro-6a,9-methanocyclohepta[a]naphthalene-4-carboxylate (6e). White powder; yield, 80\%; m.p. $168-169{ }^{\circ} \mathrm{C} ;{ }^{1} \mathrm{H}-\mathrm{NMR}\left(\mathrm{CDCl}_{3}, 300 \mathrm{MHz}\right.$, ppm): $\delta 7.50-7.44$ (m, 2H, Ar-H), 7.26-7.24 (m, 1H, Ar-H), 7.08-7.03 (m, 1H, -NH-CO-), 5.40 (ddd, J = 21, 9, 3 Hz, 1H, -P-Cㅌ-NH-), 4.78-4.65 (m, 1H, -O-CHe-CO-), 4.54-4.41 (m, 1H, -O-CHa-CO-), 4.18-4.10 (m, 2H, -O-CHe-), 4.07-3.99 (m, 1H, -O-CHa-), 3.92-3.81 (m, 1H, -O-CHa-), 2.66-2.58 (m, 1H, 15-He), 2.27 (d, J = 15 Hz, 1H, 3-He), 2.06-1.97 (m, 1H, 6-He), 1.89-1.66 (m, 6H), $1.61(\mathrm{~s}, 2 \mathrm{H}), 1.58-1.50(\mathrm{~m}, 2 \mathrm{H}), 1.46-1.41(\mathrm{~m}, 2 \mathrm{H}), 1.36-1.30(\mathrm{~m}, 6 \mathrm{H})$, 1.27-1.11 (m, 7H), 1.01-1.00 (m, 3H), 0.98-0.92 (m, 1H), 0.72-0.71 (m, 3H, 20-CH $\left.{ }_{3}\right) .{ }^{13} \mathrm{C}-\mathrm{NMR}\left(\mathrm{CDCl}_{3}\right.$, $75 \mathrm{MHz}, \mathrm{ppm}): \delta 221.98,175.83,166.68,135.15,132.96,132.62,130.75,129.67,127.25,63.81,63.50,62.81$, 56.95, 54.78, 54.27, 50.01, 48.67, 48.39, 44.05, 41.40, 39.70, 39.48, 38.02, 37.91, 37.29, 28.92, 21.99, 20.41, 19.91, 18.90, 16.42, 16.24, 13.39. HRMS $(\mathrm{m} / \mathrm{z})$ : calcd for $\mathrm{C}_{33} \mathrm{H}_{47} \mathrm{Cl}_{2} \mathrm{NO}_{7} \mathrm{P}^{+}[\mathrm{M}+\mathrm{H}]^{+}: 670.2462$, found: 670.2458.

\subsection{General Procedure for the Synthesis of Intermediates (IIa-IIe, IVa-IVj, Va-Ve, VIa-VIe)}

Chloroacetyl chloride (1.23 g, $11 \mathrm{mmol}), \mathrm{Et}_{3} \mathrm{~N}(1.11 \mathrm{~g}, 11 \mathrm{mmol})$ and different amines (10 mmol) were added to $\mathrm{CH}_{2} \mathrm{Cl}_{2}(20 \mathrm{~mL})$ and the resulting mixture was stirred at $30{ }^{\circ} \mathrm{C}$ for $2-8 \mathrm{~h}$. Then, the solvent was evaporated in vacuo, water was added $(15 \mathrm{~mL})$, the mixture was filtered and the residue was washed with water to obtain the different intermediates (Scheme 2). 


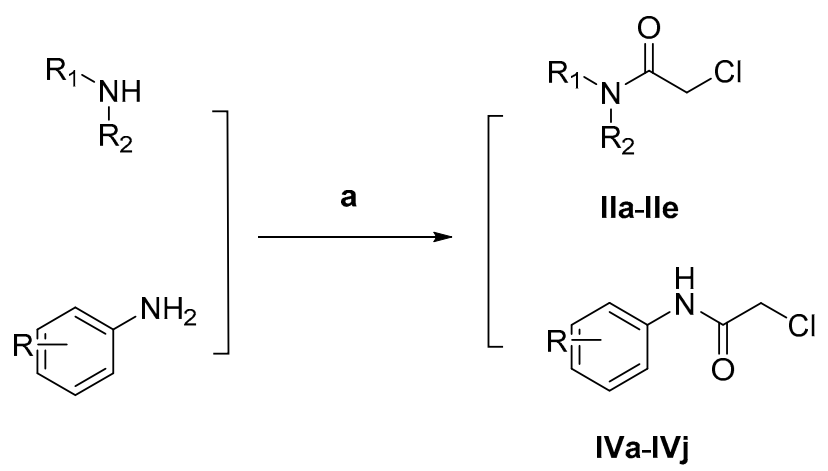

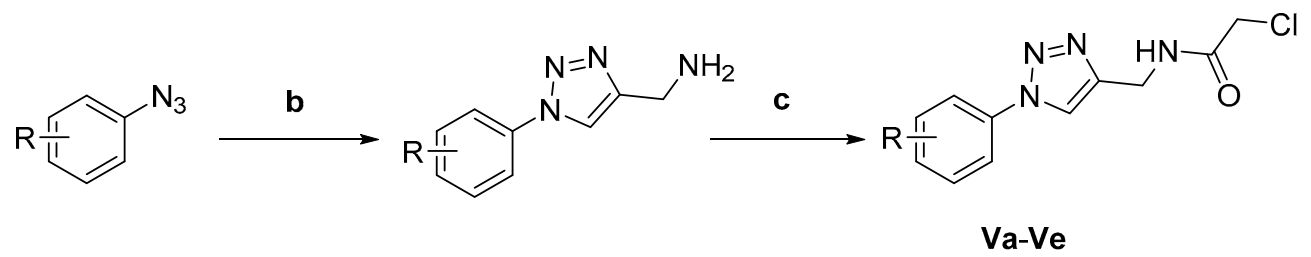<smiles>[R][R]c1ccc(C(NC(=O)CCl)P(=O)(OCC)OCC)cc1</smiles>

Scheme 2. Reagents and conditions: (a) chloroacetyl chloride, $\mathrm{Et}_{3} \mathrm{~N}, \mathrm{CH}_{2} \mathrm{Cl}_{2}, 30{ }^{\circ} \mathrm{C}$; (b) (i) propynylamine, $\mathrm{CuSO}_{4} \cdot 5 \mathrm{H}_{2} \mathrm{O}$, sodium ascorbate, $\mathrm{t}-\mathrm{BuOH} / \mathrm{H}_{2} \mathrm{O}(1: 1), 30^{\circ} \mathrm{C}$; (c) chloroacetyl chloride, $\mathrm{Et}_{3} \mathrm{~N}, \mathrm{CH}_{2} \mathrm{Cl}_{2}, 30{ }^{\circ} \mathrm{C}$; (d) diethyl phosphite, $\mathrm{CH}_{3} \mathrm{COONH}_{4}, 90{ }^{\circ} \mathrm{C}$; (e) chloroacetyl chloride, $\mathrm{Et}_{3} \mathrm{~N}$, $\mathrm{CH}_{2} \mathrm{Cl}_{2}, 30^{\circ} \mathrm{C}$.

\subsection{Biological Evaluation Materials}

3-[4,5-Dimethylthiazol-2-yl]-2,5-diphenyl-tetrazolium bromide (MTT) was purchased from Sigma Chemical Co. (St. Louis, MO, USA). The propidium iodide (PI) and Annexin V-FITC apoptosis detection kit was purchased from BD Pharmingen (San Diego, CA, USA).

\subsection{In Vitro Antiproliferative Activity}

The antiproliferative activity of the target compounds against a normal L02 cell line and the three different human cancer cell lines viz. colorectal (HCT-116), liver (BEL-7402) and liver (HepG2) were evaluated using a standard MTT-based colorimetric assay. All cell lines were obtained from the Key Laboratory of Natural Resources and Functional Molecules of the Changbai Mountain (Yanbian University, Jilin, China) and maintained in Dulbecco's modified Eagle's medium (DMEM) and RPMI Media 1640 (RPMI1640), supplemented with $10 \%$ fetal bovine serum (FBS) at $37^{\circ} \mathrm{C}$ in a humidified atmosphere containing $5 \% \mathrm{CO}_{2}$.

Cells were plated in 96-well plates at appropriate densities to ensure exponential growth throughout the experimental period $\left(9 \times 10^{3}\right.$ cells per well) and then allowed to adhere for $24 \mathrm{~h}$. Cells were then treated for $48 \mathrm{~h}$ with four serial concentrations $(1,10,50$ and $100 \mu \mathrm{M})$ of each compound. 5-fluorouracil (5-FU) was used as a positive control. After $48 \mathrm{~h}$ of incubation, $10 \mu \mathrm{L}$ of MTT solution was added to each well to a final concentration of $2 \mathrm{mg} / \mathrm{mL}$. Plates were then incubated for a further $4 \mathrm{~h}$. After incubation, the MTT solution was removed and $150 \mu \mathrm{L}$ of DMSO was added to each well for coloration. The plates were shaken vigorously for $10 \mathrm{~min}$ at room temperature to ensure complete solubilization. The optical density (OD) was read on a microplate reader (ELx800, BioTek, Highland 
Park, Winooski, VT, USA) at a wavelength of $492 \mathrm{~nm}$ and the data were subsequently analyzed. The percentage of cell growth inhibition was calculated from the following equation:

$$
\text { Inhibitory rate }(\%)=\left[\left(1-\left(\mathrm{OD}_{\text {treated }}-\mathrm{OD}_{\text {blank }}\right) /\left(\mathrm{OD}_{\text {control }}-\mathrm{OD}_{\text {blank }}\right)\right] \times 100\right. \text {. }
$$

\subsection{Colony Formation Assay}

Exponentially growing determined HCT-116 cells $\left(6 \times 10^{2}\right.$ per well $)$ were plated in 6-well plates with the Roswell Park Memorial Institute (RPMI) 1640 culture medium (Gibco, USA) containing with 10\% fetal bovine serum (FBS) (Gibco, Waltham, MA, USA). After an overnight incubation, the culture medium was removed and replaced fresh medium. Then, the cells were treated with various concentrations of compound $5 \mathbf{d}(5,10$ and $15 \mu \mathrm{M})$ dissolved in DMSO. Some cells were treated with DMSO only as a negative control. The cells were then incubated for another 7 days. Finally, the cells were fixed with $4 \%$ paraformaldehyde for $30 \mathrm{~min}$ and stained with $0.1 \%$ crystal violet for 15 min at room temperature, after which, the staining was washed with PBS until the colonies were totally cleared.

\subsection{Analysis for Cell Cycle and Apoptosis by Flow Cytometry}

HCT-116 cells were plated in 6-well plates $\left(5.0 \times 10^{5}\right.$ cells per well $)$ and incubated at $37^{\circ} \mathrm{C}$ for 24 h. Exponentially growing cells were then incubated with compound $5 \mathbf{d}$ at 5 and $15 \mu \mathrm{M}$. After $24 \mathrm{~h}$, untreated cells (control) or cells treated with compound $\mathbf{5 d}$ were centrifuged at $1000 \mathrm{rpm}$ for $10 \mathrm{~min}$ and then fixed in $70 \%$ ethanol at $-20{ }^{\circ} \mathrm{C}$ for at least $24 \mathrm{~h}$. The cells were subsequently resuspended in phosphate-buffered saline (PBS) containing $0.1 \mathrm{mg} / \mathrm{mL}$ of RNase A and $5 \mu \mathrm{g} / \mathrm{mL}$ propidium iodide (PI). The cellular DNA content for the cell cycle distribution analysis was measured by flow cytometry using a FACSCalibur flow cytometer with Cell Quest software (Becton-Dickinson, Franklin Lakes, NJ, USA), plotting at least 30,000 events per sample. The percentage of cells in the G1, S and G2 phases of the cell cycle were determined using the ModFit LT version 4.0 software package (Verity Software, Topsham, ME, USA).

Apoptosis was detected using an Apoptosis Detection Kit (Invitrogen, Eugene, OR, USA). In brief, cells were cultured in 6-well plates $\left(5.0 \times 10^{5}\right.$ cells per well) and incubated at $37^{\circ} \mathrm{C}$ for $24 \mathrm{~h}$. Cells with exponential growth were then incubated with compound $5 \mathrm{~d}$ at 5 and $15 \mu \mathrm{M}$. Following $24 \mathrm{~h}$ of incubation, the cells were collected, washed twice with PBS and once with $1 \times$ binding buffer and then stained with $5 \mu \mathrm{M}$ of annexin V-FITC and $2.5 \mu \mathrm{M}$ of PI $5 \mathrm{mg} / \mathrm{mL}$ in $1 \times$ binding buffer for $30 \mathrm{~min}$ at room temperature in the dark. Apoptotic cells were enumerated using a FACSCalibur flow cytometer with Cell Quest software (Becton-Dickinson, Franklin Lakes, NJ, USA).

\subsection{Western Blotting}

HCT-116 cells were cultured with different concentrations of compound $\mathbf{5 d}$ for $24 \mathrm{~h}$. Then, the floating cells was collected and washed two times with ice cold PBS. The pellet was resuspended in lysis buffer. After the cells were lysed on ice for $20 \mathrm{~min}$, lysates were centrifuged at $12,000 \mathrm{rpm}$ at $4{ }^{\circ} \mathrm{C}$ for 15 $\mathrm{min}$. The protein concentration in the supernatant was determined using BCA protein assay reagents. Equal amounts of protein $(50 \mu \mathrm{g})$ were resolved using sodium dodecyl sulphate-polyacrylamide gel electrophoresis (SDS-PAGE) (8-12\% acrylamide gels) and transferred to a PVDF Hybond-P membrane. Membranes were blocked with PBS containing 5\% non-fat milk for $1 \mathrm{~h}$ at room temperature. Membranes were then incubated with primary antibodies against Cyclin A (ENT1167, Elabscience, Wuhan, China), Cyclin E1 (ENT1176, Elabscience, Wuhan, China), Cyclin B1 (ENT1169, Elabscience, Wuhan, China) and $\beta$-actin (ENM0028, Elabscience, Wuhan, China), with gentle rotation overnight at $4{ }^{\circ} \mathrm{C}$. Membranes were next incubated with fluorescent secondary antibodies for $2 \mathrm{~h}$. Proteins were detected by electrochemiluminescence (Bio-Rad, Hercules, CA, USA). 


\subsection{Molecular Docking Study}

The molecular docking study was performed using Discovery Studio (DS) 2017. The protein and ligand were prepared, water molecules were deleted and a DS Server added hydrogen. The docking result was treated with DS Client. In this study, the crystal structure of the CDK2/cyclin A complex (3my5) was chosen for docking. The xyz coordinates $(-25.8518,4.7751,-23.0309$, radius $34.6 \AA)$ of CDK2/cyclin A complex residues were defined as the binding site sphere. The protocol, CDOCKER was used to perform the docking. The output poses of the ligands generated were analyzed based on the LibDockScore function.

\section{Conclusions}

In the present study, thirty-two novel isosteviol derivatives were designed, synthesized and evaluated for their antiproliferative effects against three cancer cell lines and the normal human L02 cell line. Half of these prepared compounds displayed some cytotoxic activity against the three cancer cell lines, with low cytotoxicity against the normal L02 line. In particular, compound $\mathbf{5 d}$ exhibited the most potent inhibitory activity against the three cancer cell lines. In addition, compound $\mathbf{5} \mathbf{d}$ can inhibit the colony formation of HCT-116 cells in a concentration-dependent manner. Cell cycle analysis revealed that compound $\mathbf{5 d}$ inhibited cell growth via the induction of $S$ phase arrest in HCT-116 cells. The possible mechanism of action may be correlated with down-regulation of cyclin A and cyclin E1 expression with the up-regulation of cyclin B1 expression. Our docking study also revealed the amino acids His-C71 and Lys-A56 are playing a crucial role in the binding of compound $\mathbf{5 d}$ within the active site of the CDK2/cyclin A complex. Hence, compound $\mathbf{5 d}$ may be a valuable candidate for further studies aimed at the development of effective and harmless anticancer drugs.

Supplementary Materials: The supplementary materials are available online, $1 \mathrm{H}$ and 13C-NMR spectra of these compounds are available in the supplementary materials.

Author Contributions: T.L. performed the experiments and wrote the paper. T.L. and Z.-S.Q. designed the experiments. All authors took part in data analysis and discussion. All authors read and approved the final manuscript.

Funding: This work was supported by the National Natural Science Foundation of China (No. 21662036) and research grants from the Health and Family Planning in Jilin Province science and technology backbone training program for youth (No. 2016Q047).

Conflicts of Interest: The authors declare no conflict of interest.

\section{References}

1. Jemal, A.; Siegel, R.; Ward, E.; Murray, T.; Xu, J.; Thun, M.J. Cancer statistics, 2007. CA Cancer J. Clin. 2007, 57, 43-66. [CrossRef] [PubMed]

2. Bray, F.; Moller, B. Predicting the future burden of cancer. Nat. Rev. Cancer. 2006, 6, 63-74. [CrossRef] [PubMed]

3. Newman, D.J. Natural products as leads to potential drugs: An old process or the new hope for drug discovery? J. Med. Chem. 2008, 51, 2589-2599. [CrossRef] [PubMed]

4. Nordentoft, I.; Jeppesen, P.B.; Hong, J.; Abudula, R.; Hermansen, K. Isosteviol increases insulin sensitivity and changes gene expression of key insulin regulatory genes and transcription factors in islets of the diabetic KKAy mouse. Diabetes Obes. Metab. 2008, 10, 939-949. [CrossRef] [PubMed]

5. Wong, K.L.; Yang, H.Y.; Chan, P.; Cheng, T.H.; Liu, J.C.; Hsu, F.L.; Liu, I.M.; Cheng, Y.W.; Cheng, J.T. Isostviol as a potassium channel opener to lower intracellular calcium concentrations in cultured aortic smooth muscle cells. Planta Med. 2004, 70, 108-112.

6. Xu, D.; Zhang, S.; Foster, D.J.R.; Wang, J. The effects of isosteviol against myocardium injury induced by ischaemia-reperfusion in the isolated guinea pig heart. Clin. Exp. Pharmacol. Physiol. 2007, 34, 488-493. [CrossRef]

7. Wong, K.L.; Chan, P.; Yang, H.Y.; Hsu, F.L.; Liu, I.M.; Cheng, Y.W.; Cheng, J.T. Isosteviol acts on potassium channels to relax isolated aortic strips of wistar rat. Life Sci. 2004, 74, 2379-2387. [CrossRef] 
8. Ma, J.; Ma, Z.; Wang, J.; Milne, R.W.; Xu, D.; Davey, A.K.; Evans, A.M. Isosteviol reduces plasma glucose levels in the intravenous glucose tolerance test in Zucker diabetic fatty rats. Diabetes Obes. Metab. 2007, 9, 597-599. [CrossRef]

9. Lin, L.H.; Lee, L.W.; Sheu, S.Y.; Lin, P.Y. Study on the stevioside analogues of steviolbioside, steviol and isosteviol 19-alkyl amide dimers: Synthesis and cytotoxic and antibacterial activity. Chem. Pharm. Bull. 2004, 52, 1117-1122. [CrossRef]

10. Mizushina, Y.; Akihisa, T.; Ukiya, M.; Hamasaki, Y.; Nakai, C.M.; Kuriyama, I.; Takeuchi, T.; Sugawara, F.; Yoshida, H. Structural analysis of isosteviol and related compounds as DNA polymerase and DNA topoisomerase inhibitors. Life Sci. 2005, 77, 2127-2140. [CrossRef]

11. Chen, X.; Hermansen, K.; Xiao, J.; Bystrup, S.K.; Driscoll, L.O.; Jeppesen, P.B. Isosteviol has beneficial effects on palmitate-induced $\alpha$-cell dysfunction and gene expression. PLoS ONE 2012, 7, e34361. [CrossRef] [PubMed]

12. Yasukawa, K.; Kitanaka, S.; Seo, S. Inhibitory effect of stevioside on tumor promotion by 12-o-tetradecanoylphorbol-13-acetate in two-stage carcinogenesis in mouse skin. Biol. Pharm. Bull. 2002, 25, 1488-1490. [CrossRef]

13. Wonganan, O.; Tocharus, C.; Puedsing, C.; Homvisasevongsa, S.; Sukcharoen, O.; Suksamrarn, A. Potent vasorelaxant analogs from chemical modification and biotransformation of isosteviol. Eur. J. Med. Chem. 2013, 62, 771-776. [CrossRef] [PubMed]

14. Braguinu, W.L.; Gomes, M.A.B.; Oliveira, B.H.; Garnieri, E.G.S.; Rocha, M.E.M.; Oliveira, M.B.M. Activity of isosteviol lactone on mitochondrial metabolism. Toxicol. Lett. 2003, 143, 83-92. [CrossRef]

15. Chang, F.R.; Yang, P.Y.; Lin, J.Y.; Lee, K.H.; Wu, Y.C. Bioactive kaurane diterpenoids from annona glabra. J. Nat. Prod. 1998, 61, 437-439. [CrossRef] [PubMed]

16. Kataev, V.E.; Militsina, O.I.; Strobykina, I.Y.; Kovylyaeva, G.I.; Musin, R.Z.; Fedorova, O.V.; Rusinov, G.L.; Zueva, M.N.; Mordovskoi, G.G.; Tolstikov, A.G. Synthesis and anti-tuberculous activity of diesters based on isosteviol and dicarboxylic acids. Pharm. Chem. J. 2006, 40, 473-475. [CrossRef]

17. Zhu, S.L.; Wu, Y.; Liu, C.J.; Wei, C.Y.; Tao, J.C.; Liu, H.M. Synthesis and in vitro cytotoxic activity evaluation of novel heterocycle bridged carbothioamide type isosteviol derivatives as antitumor agents. Bioorg. Med. Chem. Lett. 2013, 23, 1343-1346. [CrossRef] [PubMed]

18. Zhu, S.L.; Wu, Y.; Liu, C.J.; Tao, J.C.; Liu, H.M. Design and stereoselective synthesis of novel isosteviol-fused pyrazolines and pyrazoles as potential anticancer agents. Eur. J. Med. Chem. 2013, 65, 70-82. [CrossRef] [PubMed]

19. Wang, T.; Liu, Y.; Chen, L. Synthesis and cytotoxic activity of nitric oxide-releasing isosteviol derivatives. Bioorg. Med. Chem. Lett. 2014, 24, 2202-2205. [CrossRef]

20. Khaybullin, R.N.; Liang, X.; Cisneros, K.; Qi, X. Synthesis and anticancer evaluation of complex unsaturated isosteviol derived triazole conjugates. Future Med. Chem. 2015, 7, 2419-2428. [CrossRef] [PubMed]

21. Liu, C.J.; Yu, S.L.; Liu, Y.P.; Dai, X.J.; Wu, Y.; Li, R.J.; Tao, J.C. Synthesis, cytotoxic activity evaluation and HQSAR study of novel isosteviol derivatives as potential anticancer agents. Eur. J. Med. Chem. 2016, 115, 11-40. [CrossRef] [PubMed]

22. Liu, Y.; Wang, T.; Ling, Y.; Bao, N.; Shi, W.; Chen, L.; Sun, J. Design, synthesis and cytotoxic evaluation of nitric oxide-releasing derivatives of isosteviol. Chem. Biol. Drug Des. 2017, 90, 473-477. [CrossRef] [PubMed]

23. Liu, C.J.; Liu, Y.P.; Yu, S.L.; Dai, X.J.; Zhang, T.; Tao, J.C. Syntheses, cytotoxic activity evaluation and HQSAR study of 1,2,3-triazole-linked isosteviol derivatives as potential anticancer agents. Bioorg. Med. Chem. Lett. 2016, 26, 5455-5461. [CrossRef] [PubMed]

24. Liu, C.J.; Zhang, T.; Yu, S.L.; Dai, X.J.; Wu, T.; Tao, J.C. Synthesis, cytotoxic activity, 2D- and 3D-QSAR studies of 19-carboxyl modified novel isosteviol derivatives as potential anticancer agents. Chem. Biol. Drug Des. 2017, 89, 870-887. [CrossRef] [PubMed]

25. Liu, D.; Meng, Y.; Zhao, J.; Chen, L. Synthesis and anti-tumor activity of novel amide derivatives of ursolic acid. Chem. Res. Chin. Univ. 2008, 24, 42-46. [CrossRef]

26. Zhang, H.J.; Zhang, G.R.; Piao, H.R.; Quan, Z.S. Synthesis and characterisation of celastrol derivatives as potential anticancer agents. J. Enzyme Inhib. Med. Chem. 2017, 33, 190-198. [CrossRef] [PubMed]

27. Heller, L.; Knorrscheidt, A.; Flemming, F.; Wiemann, J.; Sommerwerk, S.; Pavel, I.Z.; Harrasi, A.A.; Csuk, R. Synthesis and proapoptotic activity of oleanolic acid derived amides. Bioorg. Chem. 2016, 68, 137-151. [CrossRef] [PubMed] 
28. Wiemann, J.; Heller, L.; Perl, V.; Kluge, R.; Strohl, D.; Csuk, R. Betulinic acid derived hydroxamates and betulin derived carbamates are interesting scaffolds for the synthesis of novel cytotoxic compounds. Eur. J. Med. Chem. 2015, 106, 194-210. [CrossRef] [PubMed]

29. Ullah, A.; Iftikhar, F.; Arfan, M.; Kazmi, S.T.B.; Anjum, M.N.; Haq, I.; Ayaz, M.; Farooq, S.; Rashid, U. Amino acid conjugated antimicrobial drugs: Synthesis, lipophilicity-activity relationship, antibacterial and urease inhibition activity. Eur. J. Med. Chem. 2018, 145, 140-153. [CrossRef] [PubMed]

30. Huang, R.Z.; Wang, C.Y.; Li, J.F.; Yao, G.Y.; Pan, Y.M.; Ye, M.Y.; Wang, H.S.; Zhang, Y. Synthesis, antiproliferative and apoptosis-inducing effects of novel asiatic acid derivatives containing $\alpha$-aminophosphonates. RSC Adv. 2016, 6, 62890-62906. [CrossRef]

31. Moosavi-Movahedi, A.A.; Hakimelahi, S.; Chamani, J.; Khodarahmi, G.A.; Hassanzadeh, F.; Luo, F.T.; Ly, T.W.; Shia, S.K.; Yen, C.F.; Jain, L.M.; et al. Design, synthesis and anticancer activity of phosphonic acid diphosphate derivative of adenine-containing butenolide and its water-soluble derivatives of paclitaxel with high antitumor activity. Bioorg. Med. Chem. 2003, 11, 1303-4313. [CrossRef]

32. Khaybullin, R.N.; Zhang, M.; Fu, J.; Liang, X.; Li, T.; Katritzky, A.R.; Okunieff, P.; Qi, X. Design and synthesis of isosteviol triazole conjugates for cancer therapy. Molecules 2014, 19, 18676-18689. [CrossRef] [PubMed]

33. Huang, X.; Shen, Q.K.; Zhang, H.J.; Li, J.L.; Tian, Y.S.; Quan, Z.S. Design and Synthesis of novel dehydroepiandrosterone analogues as potent antiproliferative agents. Molecules 2018, 23, 2243. [CrossRef] [PubMed]

34. Xu, S.; Yao, H.; Luo, S.; Zhang, Y.K.; Yang, D.H.; Li, D.; Wang, G.; Hu, M.; Qiu, Y.; Wu, X.; et al. A novel potent anticancer compound optimized from a natural oridonin scaffold induces apoptosis and cell cycle arrest through the mitochondrial pathway. J. Med. Chem. 2017, 60, 1449-1468. [CrossRef] [PubMed]

35. Hileman, E.O.; Liu, J.; Albitar, M.; Keating, M.J.; Huang, P. Intrinsic oxidative stress in cancer cells: A biochemical basis for therapeutic selectivity. Cancer Chemother. Pharmacol. 2004, 53, 209-219. [CrossRef]

36. Luo, G.S.; Muyaba, M.; Lyu, W.; Tang, Z.C.; Zhao, R.H.; Xu, Q.; You, Q.D.; Xiang, H. Design, synthesis and biological evaluation of novel 3-substituted 4-anilino-coumarin derivatives as antitumor agents. Bioorg. Med. Chem. Lett. 2017, 27, 867-874. [CrossRef]

37. Kalra, S.; Joshi, G.; Munshi, A.; Kumar, R. Structural insights of cyclin dependent kinases: Implications in design of selective inhibitors. Eur. J. Med. Chem. 2017, 142, 424-458. [CrossRef]

38. Odajima, J.; Wills, Z.P.; Ndassa, Y.M.; Terunuma, M.; Kretschmannova, K.; Deeb, T.Z.; Geng, Y.; Gawrzak, S.; Quadros, I.M.; Newman, J. Cyclin E constrains Cdk5 activity to regulate synaptic plasticity and memory formation. Dev. Cell 2011, 21, 655-668. [CrossRef]

39. Chen, Y.J.; Dominguez-Brauer, C.; Wang, Z.; Asara, J.M.; Costa, R.H.; Tyner, A.L.; Lau, L.F.; Raychaudhuri, P. A conserved phosphorylation site within the forkhead domain of FoxM1B is required for its activation by cyclin-CDK1. J. Biol. Chem. 2009, 284, 30695-30707. [CrossRef]

40. Jo, H.J.; Song, J.D.; Kim, K.M.; Cho, Y.H.; Kim, K.H.; Park, Y.C. Diallyl disulfide induces reversible G2/M phase arrest on a p53-independent mechanism in human colon cancer HCT-116 cells. Oncol. Rep. 2008, 19, 275-280. [CrossRef]

41. Clarke, P.R.; Allan, L.A. Cell-cycle control in the face of damagea matter of life or death. Trends Cell Biol. 2009, 19, 89-98. [CrossRef] [PubMed]

42. Tiwari, S.V.; Siddiqui, S.; Seijas, J.A.; Vazquez-Tato, M.P.; Sarkate, A.P.; Lokwani, D.K.; Nikalje, A.P.G. Microwave-assisted facile synthesis, anticancer evaluation and docking study of N-((5-(Substituted methylene amino)-1,3,4-thiadiazol-2-yl)methyl) benzamide derivatives. Molecules 2017, 22, 995. [CrossRef] [PubMed]

Sample Availability: Not available. 